\title{
Imaging sedimentary basins from high-resolution aeromagnetics and texture analysis ${ }^{\text {h }}$
}

\author{
D. Nathan*, A.Aitken, E.J.Holden, J. Wong \\ Centre for Exploration Targeting, Perth, Western Australia, Australia
}

\begin{abstract}
A B S T R A C T

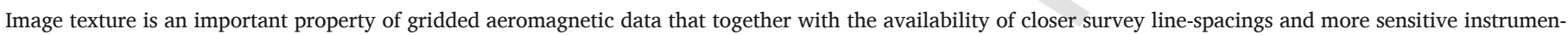

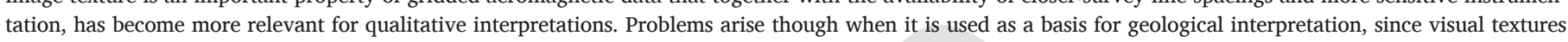

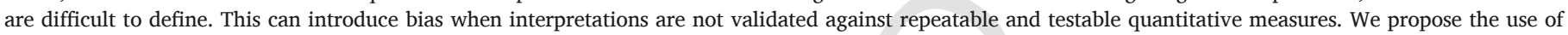

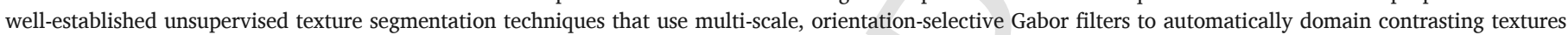

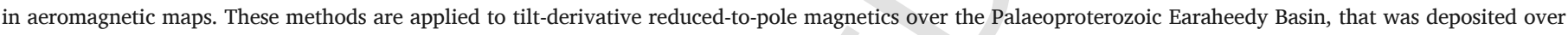

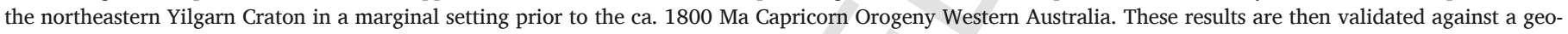

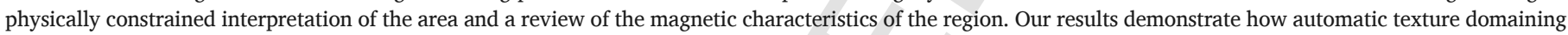

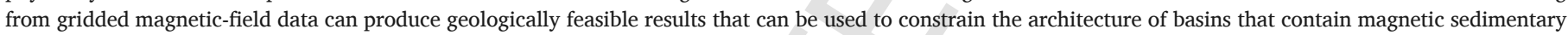
rocks.
\end{abstract}

\section{Introduction}

The availability of high-resolution aeromagnetic data has made their application an important tool for mapping regional geology (Balsley, 1952; Pilkington, 1998; Pilkington and Keating, 2004). This is especially the case in areas with limited and sparse outcrop where it becomes necessary to correlate interpreted magnetic rock packages with exposed lithologies (Aitken and Betts, 2009; Gunn et al., 1995; Tschirhart and Morris, 2015). While aeromagnetics is often applied for the interpretation of the magnetic basement (Cordell and Grauch, 1985; Isles and Rankin, 2013; Steenland, 1963), the compilation of higher-resolution gridded aeromagnetic data has also enabled other types of anomaly patterns to be used for qualitative interpretations of near-surface features (Nabighian et al., 2005). An example of this is the identification of lithological contacts that are characterized by changes in high spatial frequency textures or magnetic fabrics anomaly patterns (Gunn, 1997; Olaniyan et al., 2013). Uncertainties arise though when different lithological units have similar magnetic intensities and texture (Aitken et al., 2008), or when magnetic anomaly pattern changes are a result of geological processes that have not been considered in the interpretation (Grant, 1985). Thus, quantitative and repeatable methods for describing the complexity of changes in magnetic characteristics, such as intensity and texture, are essential for assessing the uncertainty of a geologic interpretation from aeromagnetics (Aitken et al., 2013).

The physical basis and motivation for the application of aeromagnetic surveys in geological mapping and exploration geophysics is that changes in net magnetization can be mapped as contacts (Pilkington and Keating, 2004). The net rock magnetization though is controlled by the composition and content of minerals, i.e. magnetite, hematite, or pyrrhotite, that often are considered accessory to the main mineral assemblage which conventionally are classified by their silicate and carbonate mineralogy (Grant, 1985). As a result a single lithology may exhibit a wide range of magnetic properties (Clark and Emerson, 1991). Thus the identification of a lithological contact from a gridded aeromagnetic map will be ambiguous without either a clear geological context and/or petrophysical measurements to constrain the identification of the contrasting regions (Singhroy and Pilkington, 2014). In the context of sedimentary basins, differing sedimentary environments and variations in alteration processes lead to differing tendencies for rocks to exhibit an induced magnetization (Dunlop, 1997; Reynolds et al., 1990). When the magnetization of stratiform magnetic anomalies are modelled though, the architecture of the basin, in terms of its stratigraphic and structural modifications, can be interpreted and contacts can be delineated (Austin et al., 2017; Dentith and Cowan, 2011).

is David Nathan was the primary researcher in methodology development and implementation. Alan Aitken provided expertise in geological background of Earaheedy. Eun-Jung Holden and Jason Wong supported the direction of methodology and implementation. * Corresponding author.

E-mail address: david.nathan@research.uwa.edu.au (D. Nathan) 
Different image analysis approaches exist which have been applied to automatically segment magnetic images based on magnetic feature characteristics such as amplitude or texture. One of these approaches is to take magnetic discontinuities and assume they are geological contacts (Blakely and Simpson, 1986; Cordell and Grauch, 1985). This has resulted in a number of derivative-based filters, such as the first vertical-derivative (Nabighian, 1984) and theta map (Wijns et al., 2005), which are used to enhance edges in gridded magnetic data (Pilkington and Tschirhart, 2017). Another approach that can be used is image segmentation where homogeneous pixels are grouped together based on characteristics such as raw pixel value and/or texture (Blaschke, 2010).

Various automated analysis methods have been proposed to utilise magnetic data for lithology mapping and image segmentation. In particular, machine learning methods have been used to integrate magnetic data with other geophysical and remote sensing data for lithoclassification (Kuhn et al., 2018; Yu et al., 2012). These methods in general use a multivariate approach, so that various data sources such as ASTER, Digital Elevation Models, Gamma ray spectrometry, as well as magnetic susceptibility are combined to classify lithologies (Cracknell and Reading, 2014; Masoumi et al., 2017). We suggest in this paper though that the visual texture of gridded magnetic data is an overlooked variable that can be utilised in these approaches.

The visual texture of an image can be defined by the statistics of the spatial/spatial-frequency distribution of pixels and amplitudes, but how texture models relate to texture perception remains an active area of vision research (Landy, 2013; Wallis et al., 2017). In image processing and computer vision, texture analysis models can be broadly separated into four categories (Tuceryan and Jain, 1999): (1) statistical methods, such as co-occurrence matrices (Haralick, 1979), (2) geometric methods including Voronoi polygon features (Tuceryan and Jain, 1990), (3) model based methods such as Markov random fields analysis (Cross and Jain, 1983), and (4) signal processing methods which include Gabor and wavelet techniques (Jain and Farrokhnia, 1991). In geophysics, common texture measures for gridded potential-field data are restricted to statistical methods, such as the grey level co-occurrence matrix (Cooper, 2004, 2009; Cooper and Cowan, 2005; Dentith, 1995), entropy (Aitken et al., 2013; Holden et al., 2008, 2012) and fractal dimension (Dentith et al., 2000; Dhu et al., 1999, 2000).

These existing approaches in the geophysics literature treat texture as a single channel without any orientation-selectivity or frequency-dependency which are properties that have been shown to be essential to the signal processing in human visual systems (De Valois et al., 1982b, 1982a; Hubel and Wiesel, 1962). There is also evidence to suggest that the perception of the textural characteristics of images can be better modelled as a multi-channel system tuned to different orientations and scales (Bovik et al., 1990). A bank of 2D Gabor filters, which are band-pass filters that are orientation-selective, are commonly used in image processing as a multi-channel approach to texture analysis (Randen and Husoy, 1999). Previous applications of Gabor filters to gridded magnetic data have focused on edge enhancement for interpreting lineaments (Holden et al., 2016; Sertcelik et al., 2013) and not groupings of magnetic rock package regions. We apply the methods of Jain and Farrokhnia (1991) to segment gridded aeromagnetic data into contrasting regions of texture and demonstrate how together with specific choices of geophysical filters these can be applied to automatically generate a geophysical domain map.

An important aspect of the magnetic texture domaining method that is developed in this paper that we highlight here is that the texture of a magnetic rock package is defined as an ensemble of source edges with similar orientation and lateral scale. While our approach of texture domaining is similar to the work of Shankar et al. (2006) we include the specific aim of characterizing magnetic domains by scale and orientation using Gabor filters. To enhance these characteristics for segmentation we apply the tilt-angle filter (Miller and Singh, 1994) to reduced-to-pole (RTP) gridded total-magnetic-intensity (TMI) data. This has the dual effect of normalizing amplitudes, variations of which often reflect depth of source, as well as improving the resolution of close-spaced sources respectively (Dentith, 2014). An experiment is then conducted using the tilt-derivative RTP magnetic data from the region including the Palaeoproterozoic Earaheedy Basin in Western Australia (Fig. 1) by comparing the texture domaining output with an independent geological interpretation of the basin stratigraphic architecture and basement.

\section{Methods}

We present an approach to automatically characterize the stratigraphic architecture from gridded aeromagnetics and texture segmentation here. The general outline involves firstly applying the tilt-angle filter to the reduced to pole aeromagnetic survey data to improve edge detection. Next, texture analysis is performed by constructing and applying a Gabor Filter bank at different orientations and varying scales, so that each pixel has a filter response at each orientation and scale, representing local texture centred at the pixel. This data is then clustered so that each pixel is assigned to one of a pre-defined number of groups, which have similar scale and orientation. Finally, a mode filter is used to smooth the labelled regions.

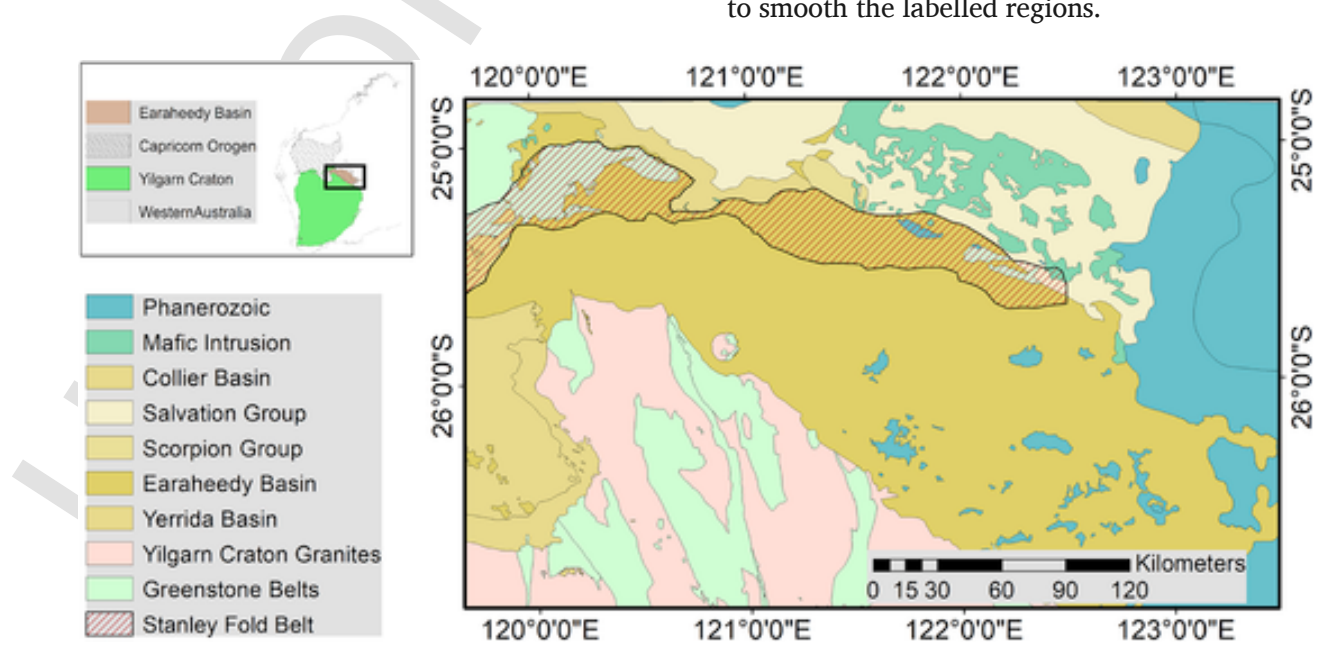

Fig. 1. Earaheedy Basin 1:500 k map (Geological Survey of Western Australia, 2017) and Stanely Fold Belt (Williams et al., 2004). 


\subsection{Preprocessing}

We apply our texture segmentation to the phase-based tilt angle (Miller and Singh, 1994). This filter is calculated as the inverse tangent of the ratio of the first-vertical derivative and the total-horizontal gradient for gridded magnetic data $F$ (see Equation (1)).

$$
\operatorname{TILT}(x, y)=\tan ^{-1} \frac{\frac{\partial F}{\partial z}}{\sqrt{\left(\frac{\partial F}{\partial x}\right)^{2}+\left(\frac{\partial F}{\partial y}\right)^{2}}}
$$

The benefit of the tilt-angle is that when applied to a reduced-to-pole magnetic field, the maximum response is centred over the source -as in the first-vertical derivative- but also that the amplitude is normalized by the total-horizontal gradient so that the maximum response is similar for deep and shallow sources (Dentith, 2014). This allows the texture segmentation of the gridded aeromagnetic data not to be dominated by the amplitude of magnetization but instead characterized by the scale and orientation of causative bodies.

\section{Texture analysis \& domaining}

\subsection{Gabor Filter bank}

In signals processing, the uncertainty principle implies that a signal cannot be localized in both time and frequency. In the case of two-dimensional images this means that both the frequency and spatial position cannot be exactly known (Petrou and García Sevilla, 2006). It was demonstrated by Gabor (1946) though, that the optimal function that has the minimal tradeoff in the uncertainty principle is the Gabor function, which is the product of a Gaussian function and a sinusoidal function (see Equation (2)). In this 1D case, $t$ is time, $\omega$ is frequency and $\sigma$ is the standard deviation of the Gaussian function.

$g(t) \underline{\underline{\text { defe }}}-\frac{\left(t-t_{0}\right)^{2}}{2 \sigma^{2}} i \omega_{0} t$

This was extended to two dimensions by Daugman (1985) and applied to images. In the 2D we have that for a given image $I(x, y)$ of size $M \times N$ dimensions, the 2D Gabor filter $g(x, y)$ in the spatial domain is Equation (3) where $\left(x_{0}, y_{0}\right)$ is the center of the filter, $\left(u_{0}, v_{0}\right)$ is the frequency of the sinusoidal function, and $(\alpha, \beta)$ control the standard deviation of the Gaussian function in the $x$ and $y$ directions. It is common in image processing to refer to the 2D Gaussian function as the Gaussian window, and the parameters $(\alpha, \beta)$ as the bandwidths of the window.

$$
\begin{aligned}
g(x, y)=\exp \{- & \pi\left[\alpha^{2}\left(x-x_{0}\right)^{2}+\beta^{2}\left(y-y_{0}\right)^{2}\right] \\
+ & \left.2 \pi i\left[u_{0}\left(x-x_{0}\right)+v_{0}\left(y-y_{0}\right)\right]\right\} .
\end{aligned}
$$

By assuming the filter is centred at the origin and using polar coordinates, Equation (3) can be rearranged to Equation (4) where $\lambda=u_{0}$ and $\theta$ is the angle between the image plane and the Gaussian window.

$g(x, y)=\exp \left\{-\pi\left(\alpha^{2} \widetilde{x}^{2}+\beta^{2} \widetilde{y}^{2}\right)\right\} \cos (2 \pi \lambda \tilde{x})$.

where

$\widetilde{x}=x \cos \theta+y \sin \theta$

$\tilde{y}=-x \sin \theta+y \cos \theta$.

The Fourier domain representation of $g(x, y)$ is $G(u, v)$ in Equation (5) where it represents a Gaussian with $\lambda$ frequency units shifted along the $u$ axis and counterclockwise rotation by an angle $\theta$. This allows fil- ters to be designed that remove all frequencies in the transformed image that are outside of a band that spatially correspond to a particular scale $\lambda$ and orientation $\theta$ (Nava et al., 2011). To be able to represent all frequencies in the Fourier representation of an image, we then need to construct a set of filters that cover the entire range of frequencies. Each filter in this filter bank is then applied to the original image in the frequency domain which when the inverse transform is applied results in a stack of images, each of which says where in the image the filter's band of frequencies can be found.

$$
\begin{aligned}
G(u, v) & =\exp \left\{-\pi\left[\frac{(\widetilde{u}-\lambda \cos \theta)^{2}}{\alpha^{2}}+\frac{(\widetilde{v}+\lambda \sin \theta)^{2}}{\beta^{2}}\right]\right\} \\
& +\exp \left\{-\pi\left[\frac{(\widetilde{u}+\lambda \cos \theta)^{2}}{\alpha^{2}}+\frac{(\widetilde{v}+\lambda \sin \theta)^{2}}{\beta^{2}}\right]\right\}
\end{aligned}
$$

where

$\widetilde{u}=u \cos \theta+v \sin \theta$

$\widetilde{v}=-u \sin \theta+v \cos \theta$.

A known limitation of Gabor filter banks is that the DC component is non-zero so that the overlap between scales at lower frequencies is proportionally much less than higher frequencies in the Fourier domain (Fischer et al., 2007). The approach by Field (1987) to separate the filter into radial $\rho$ and angular $\theta$ components and take the logarithm of the radial component (see Equation (6)) limits the effect of this which has also been shown to improve texture segmentation (Nava et al., 2011).

We use Gabor filter parameter values derived by Kovesi (1999) that are developed for edge detection using phase congruency. Here each scale is multiplied by a factor of 2.2 with a minimum $\lambda$ of 3 , the radial standard deviation $\sigma_{\rho}$ to be 0.55 of the center frequency $\lambda$ and angular standard deviation $\sigma_{\theta}$ to be 1.3 of the orientation window $\theta-\theta_{0}$. This together with the scale factor of 2.2 and an orientation window size of $30^{\circ}$ approximately covers the entire energy spectrum in the frequency domain (Petrou and García Sevilla, 2006). The number of scales can be varied with these parameter values without losing coverage of the entire energy spectrum. For further explanation of how these parameters can be defined, we refer the reader to Petrou and García Sevilla (2006).

$G(\rho, \theta)=\exp \left\{-\frac{\log ^{2}\left(\frac{\rho}{\lambda}\right)}{2 \log ^{2}\left(\frac{\sigma_{\rho}}{\lambda}\right)}\right\} \exp \left\{-\frac{\left(\theta-\theta_{0}\right)^{2}}{2 \sigma_{\theta}^{2}}\right\}$

To demonstrate the Gabor filter response of magnetic bodies, synthetic forward modelled data of three parallel rectangular prisms at the same depth in four orientations is presented in Fig. 2. The forward-model were calculated using the Fatiando package assuming that the magnetization of the bodies has an inclination and declination of 0 (Uieda et al., 2013). The number of scales are set to 4 to compare the four orientations responses, and the relative response of each scale and orientation is presented in Fig. 3 and Fig. 4 respectively. These are calculated by taking the mean filter response for each filter and then summing across scales and orientations separately and taking the proportion for each scale or orientation. The filter response across scales in Fig. 3 shows how the relative orientation of the bodies to the N-S direction changes the response across scales so that smaller scale responses are stronger when the bodies are perpendicular to the regional field and larger scales responses are stronger when they are parallel. The filter responses across orientations in Fig. 4, also show even though the distribution of responses for bodies oriented at $45^{\circ}$ to the regional field (Rotation $45^{\circ}$ and Rotation $135^{\circ}$ ) are identical across scales (Fig. 3), they have opposite responses across their orientations. 


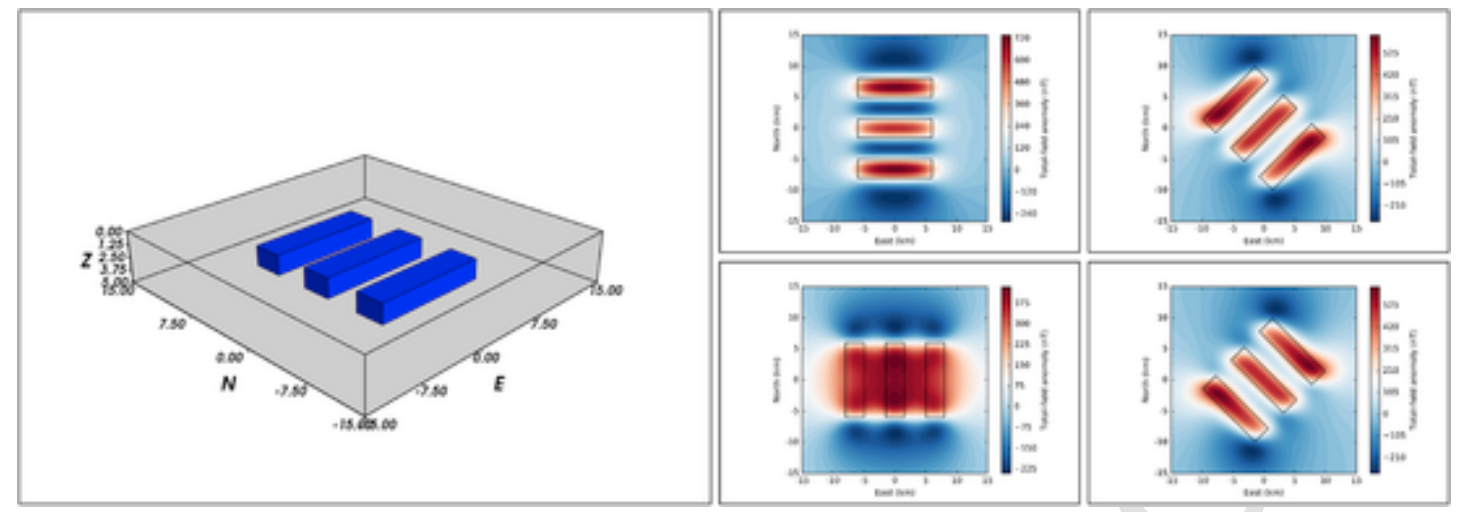

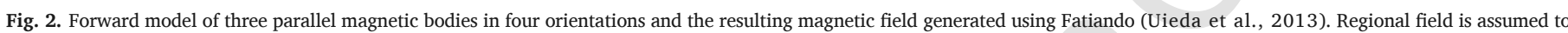
have an inclination and declination of $0^{\circ}$, so that the total field anomaly is reduced-to-equator.
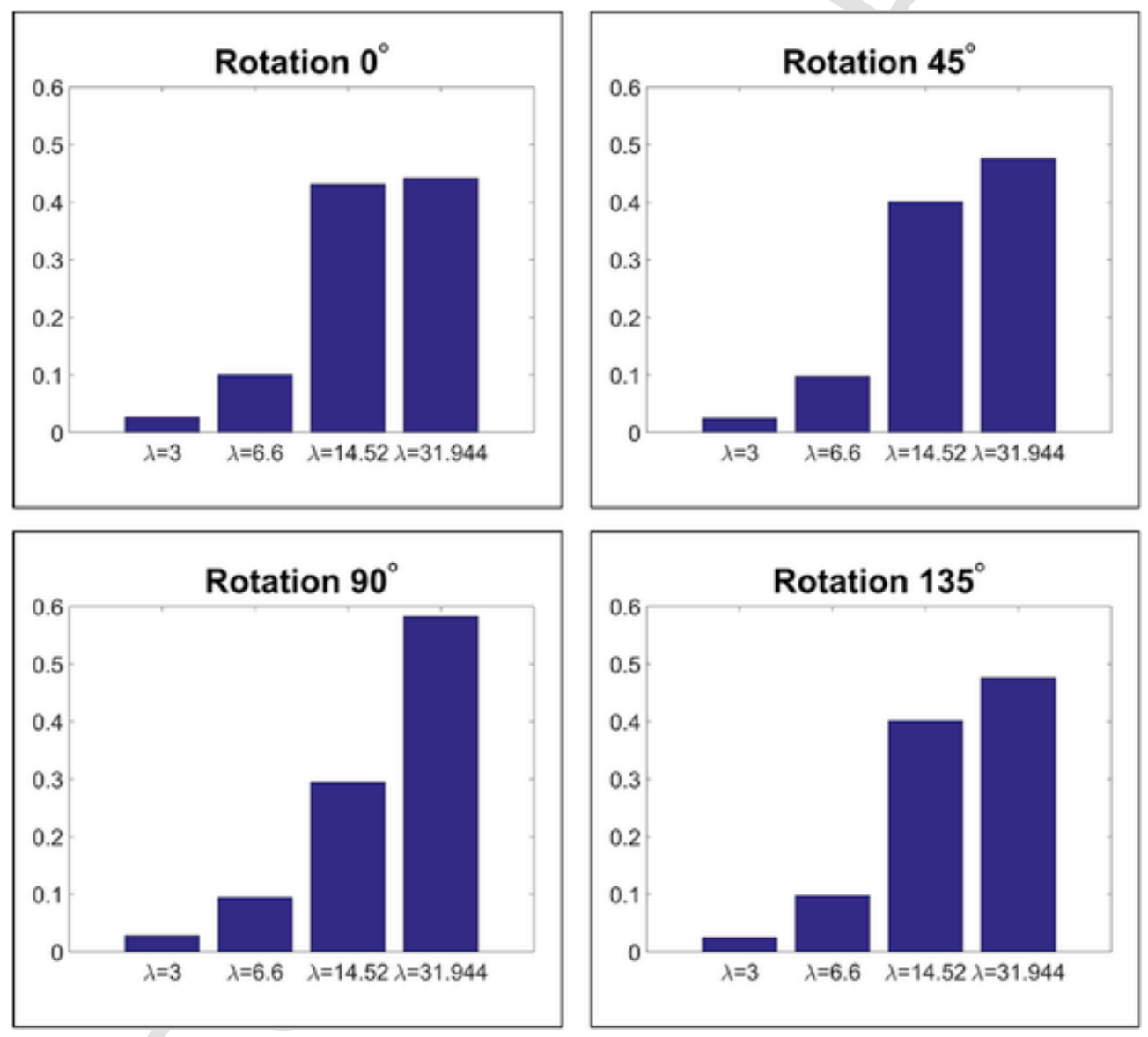

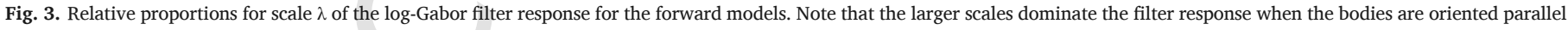
to the regional magnetic field (Rotation $90^{\circ}$ ), while smaller scales are stronger when they are perpendicular (Rotation $0^{\circ}$ ).

\subsection{Texture domaining}

Since each log-Gabor filter gives a localized response, Jain and Farrokhnia (1991) suggests a Gaussian filter for each scale where the size of the standard deviation is proportional to the scale. This blurring ensures that the responses can be compared across scales in the multi-channel filtering system, and is the same principle as the Gaussian scale-space used in computer vision and image processing for multi-scale signal representations (Lindeberg, 1994).

The filter-bank response from the image is then clustered using k-means (Lloyd, 1982). This involves first specifying k centroid ini- tial points in the filter-bank response space. Each pixel is then assigned to the centroid it is closest to. For each centroid, the mean filter-bank response of the assigned pixels is then calculated, and the difference between the centroid and mean filter-bank response is compared for the $\mathrm{k}$ centers. If the difference is greater than a defined tolerance, the centroid is updated to the mean filter-bank response and the process is repeated. We define our tolerance as $1 \mathrm{E}-5$ with a maximum of 10,000 steps. The multi-variate distribution input data from across the filters should result in responses in the spatial domain that smoothly change so that $\mathrm{k}$-means is desirable over other centroid-based clustering such as k-medians. Moreover, since we use a per-pixel response, density-based clustering would be prohibitively time-complex to compute. 

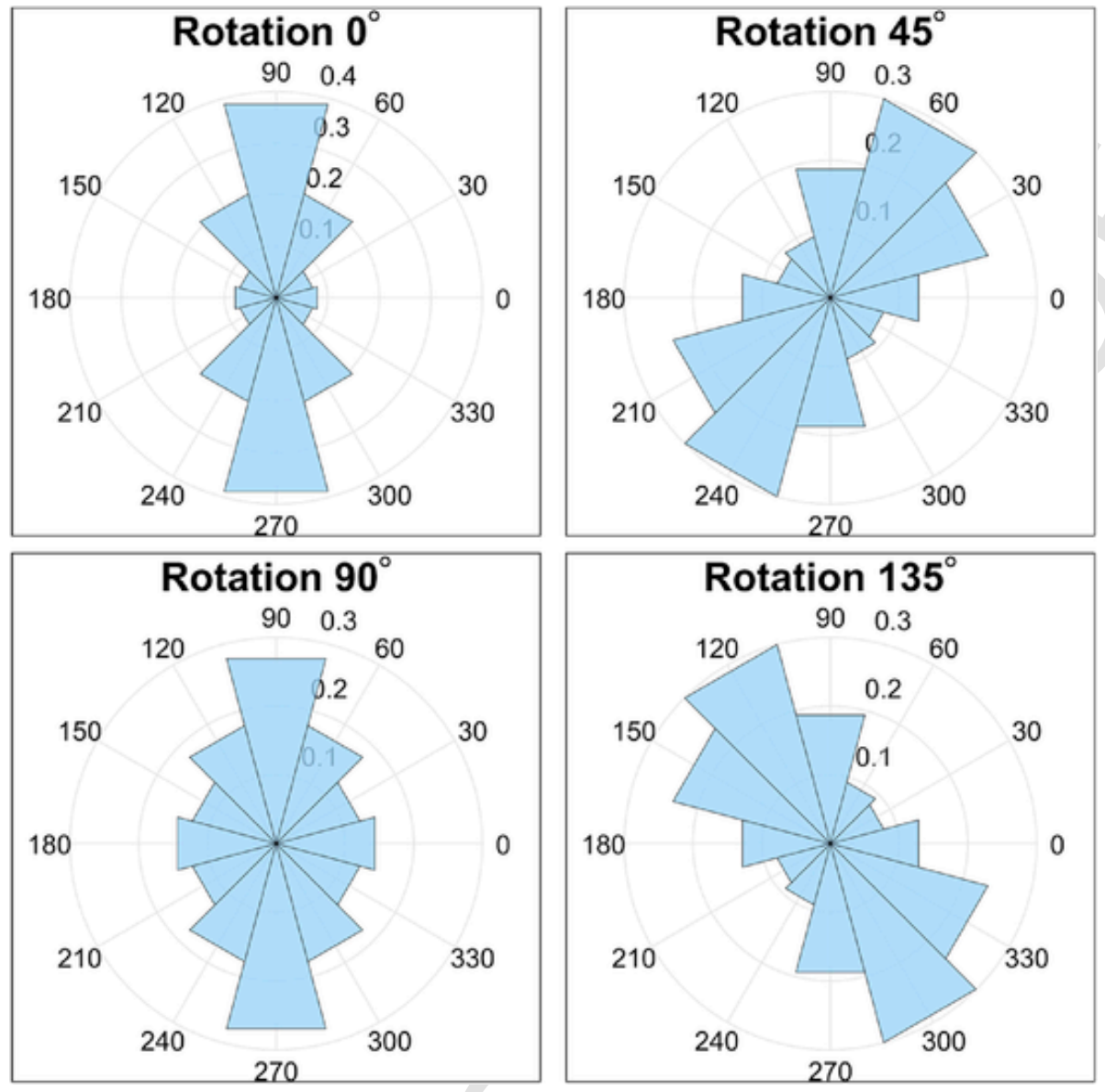

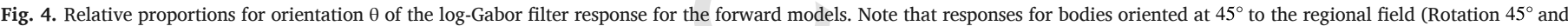
Rotation $135^{\circ}$ ) are identical across scales (Fig. 3), but have opposite responses across orientations.

To demonstrate the behavior of clustering on this filter-bank, we generate a $256 \times 256$ image that is composed of five examples of gridded RTP aeromagnetic data texture that each vary in scale and orientation (see Fig. 5). The clustering is applied without any spatial consideration since the Gaussian filter that is applied across scales will already compensate for this. Thus, for an image $I$ with $M$ columns and $N$ rows there are $M N$ sample points, with the dimension of the sample vector for the point being the number of scales multiplied by the number of orientations. For the example in Fig. 5, we use a filter bank with 4 scales $(\lambda=\{3,6.6,14.52,31.94\})$ and 6 orienta- tions $\left(\theta=\left\{0^{\circ}, 30^{\circ}, 60^{\circ}, 90^{\circ}, 120^{\circ}, 150^{\circ}\right\}\right)$. This results in a filter-bank composed of $256 \times 256=65536$ sample points where the sample vector for each point has $4 \times 6=24$ dimensions. The number of scales was set to 4 since the example aeromagnetic data grid textures were chosen to represent 4 different scales, which from smallest to largest are (1) bottom right, (2) bottom left, (3) top left and right, and (4) center (Fig. 5). The number of clusters that were used in Fig. 5 was set to 5 to correspond to the five example textures. Note that the colours in Fig. 5 correspond to different clusters.
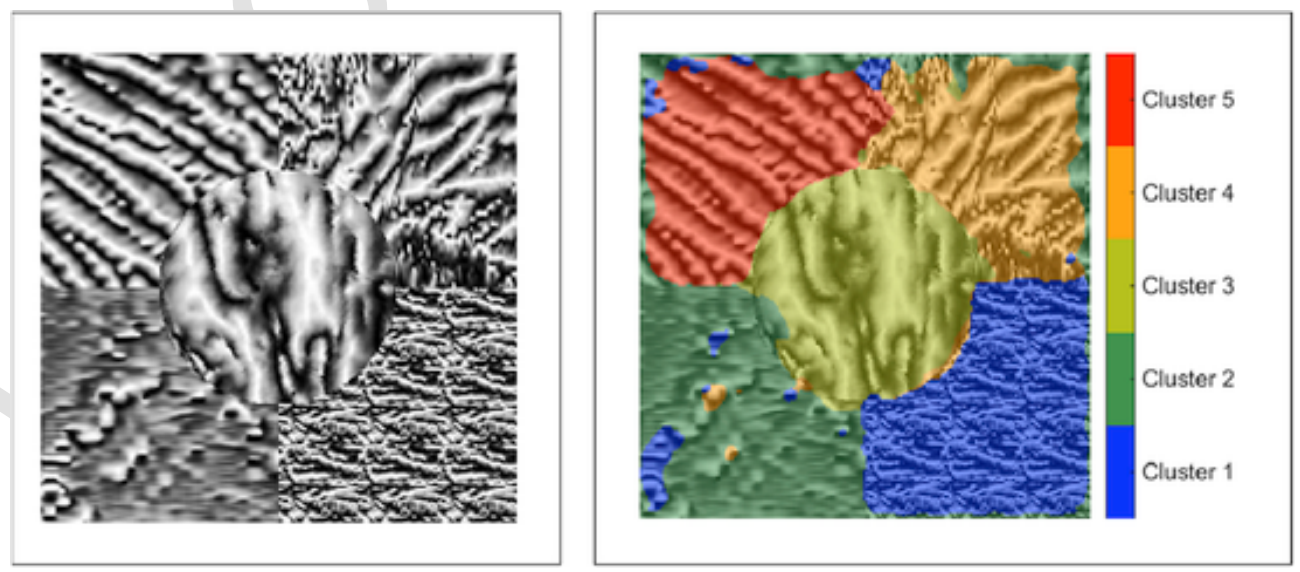

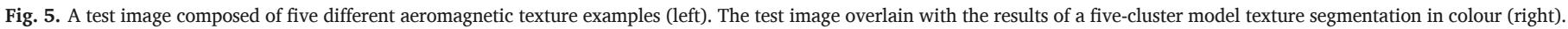


To visualize the characteristics of each cluster, the cluster center components are summed across all orientations for a given scale and normalized across all scales (see Fig. 6 top). This is also repeated for each orientation across scales (see Fig. 6 bottom). The normalized sum of each dimension in each cluster center shows the textural characteristics of the associated segment in the image. Cluster 1 can be seen to be horizontally dominate at the $90^{\circ}$ orientation while dominant at the lower scale of 6.6 cells. This is contrasted with Cluster 3 where the orientation is vertically dominant in the $0^{\circ}$ and $150^{\circ}$ range but also with stronger response at the larger scales of 14.52 and 31.94 cells.

\section{Study area: geology and magnetic characteristics}

The Earaheedy Basin lies on the northeastern margin of the Yilgarn Craton and is also included in the southeastern part of the Capricorn Orogen in Western Australia (see Fig. 1). The region comprises three main tectonic elements: the Archean Yilgarn Craton, Paleoproterozoic Basins, and Mesoproterozoic Basins. The Yilgarn Craton forms the basement of the region with the main lithological division between the granites and greenstone belts which exhibit the typical magnetic characteristic texture of Archean terranes. The granites are associated with a variety of magnetic textures, but at large scales can be divided into suites with different magnetic anomaly patterns and trends (Whitaker and Bastrakova, 2002). At smaller scales, these granites possess a variety of heterogeneities, but commonly a sub-linear east-west trending fabric is observed due to deformation and Proterozoic dyke intrusions (Fig. 8 and Fig. 9). Greenstone belts have well-banded magnetic characters, with both highs and lows reflecting extensive lithostratigraphic sequences of volcanic and sedimentary rocks. Magnetization within these rocks is strongly associated with lithology and alteration (Bourne et al., 1993; Williams, 2009), leading to a lineated appearance at the scale of kilometres (Fig. 9).

Paleoproterozoic Basins include the Yerrida and Earaheedy Basins, for each of which the geology was recently summarised by Occhipinti et al. (2017). The Yerrida Basin comprises the 2200 to $1990 \mathrm{Ma}$ Windplain Group, and the overlying Moologool Group, which is not well dated. In exposure, the Yerrida Basin contains siliciclastic sedimentary rocks, carbonates and cherts, with less common exposures of volcanic and volcaniclastic rocks and dolerites. None of these units are substantially magnetised, except locally, and the magnetic intensity of the Yerrida Basin reflects mainly the attenuation of the signal from the Yilgarn Craton beneath the sedimentary package.

Using the revised classification of Occhipinti et al. (2017), the Earaheedy basin comprises the Tooloo and Miningarra Groups, as well as the intervening Frere Formation. The 1990 to 1940 Ma Tooloo Group includes sandstones, siltstones and a prominent carbonate unit (Yelma Formation). The Imbin Inlier and the Troy Creek Schist may also be part of the Tooloo Group. Undeformed and unmetamorphosed Tooloo Group rocks are not substantially magnetised (Fig. 10), however, the Stanley Fold Belt preserves weakly to moderately magnetised examples including the Troy Creek Schist, and schistose metasedimentary rocks (Fig. 11). The Frere Formation formed ca 1890 Ma (Rasmussen et al., 2012), with deposition of granular iron formation (GIF), siltstones, shales and cherts and carbonate rocks all in a shallow marine setting (Akin et al., 2013; Occhipinti et al., 2017) (Fig. 10). Magnetic susceptibility variations within the Frere Formation has been analysed in detail from diamond-drill-core (TDH-26 -Fig. 10). Susceptibilities were measured with an Exploranium KT-9 susceptibility meter, that has an accuracy of 1 e-5 SI, and an upper limit of 1 SI. Below $390 \mathrm{~m}$, this core intersects the very low to moderate susceptibility carbonates of the Yelma Formation. Above $390 \mathrm{~m}$ the core intersects moderate-susceptibility interbedded siliceous-GIF, stromatolitic carbonate-GIF and siltstones, with occasional high magnetic susceptibility associated with magnetite-bearing shale horizons. From $320 \mathrm{~m}$ to $220 \mathrm{~m}$, the frequency and thickness of these high and very high magnetic sus- ceptibility horizons increases, and moderate susceptibility ferruginous-GIF becomes dominant over siliceous-GIF. From $218 \mathrm{~m}$ to $176 \mathrm{~m}$ a low to moderate susceptibility siltstone unit is observed. The upper part of the core is dominated by ferruginous-GIF, siltstone of moderate susceptibility and magnetite-bearing shale, with reducing frequency and thickness of the high and very high susceptibility horizons. The magnetic susceptibility of the Frere Formation is correlated with lithology and magnetic data can therefore be used to laterally differentiate magnetic GIF-dominated units from non-magnetic siliciclastic units and the carbonate-dominated Windidda member (non-magnetic.) Texture within the GIF-dominated units is quite variable, from fracture-dominated patterning, to a well-lineated patterning, depending on the degree of deformation. The southern Earaheedy Basin possesses shallow north-dipping strata, whereas the strata in the north are steeply-dipping, and so the Frere Formation signal is much enhanced in the north of the basin (Fig. 7). The overlying Miningarra Group is dominated by siliciclastic and carbonate rocks deposited in a shallow marine to terrestrial setting between $\sim 1880$ and $1815 \mathrm{Ma}$. The Miningarra Group is thick, with several kilometres of sedimentary rocks preserved, but non-magnetic. Consequently, its magnetic signature is defined by the attenuation of Yilgarn Craton and Frere Formation signals beneath a thick blanket of non-magnetic rocks.

The granular iron-formations (GIF) of the Frere Formation have a strong magnetic signature that can also be used to outline the basin structure (Morris et al., 2003; Pirajno et al., 2009). To the north of the Stanley Fold Belt, these sequences are overlain by Mesoproterozoic basins including the Scorpion, and Salvation basins (Morris and Pirajno, 2005). The Scorpion Group comprises siliciclastic sedimentary rocks, dolomites and evaporites deposited between 1640 and 1200 Ma. The Salvation Group has similar characteristics but was deposited between 1460 and $1066 \mathrm{Ma}$. None of these rocks are clearly associated with a magnetic signal due to the influence of later dolerite sills.

The Salvation and Earaheedy basins are intruded by the Glenayle and Prenti Dolerites respectively. These dolerite sill-complexes are associated with the Warakurna large igneous province, and were intruded between 1080 and $1060 \mathrm{Ma}$ (Wingate et al., 2004). These dolerites are strongly magnetic, and coincide with magnetic field highs that are characterized by intense short-wavelength fracture-dominated patterns which previously have been used to map their extent (Morris and Pirajno, 2005; Shevchenko, 2000).

\section{Study area: airborne geophysical surveys}

The aeromagnetic data grid was compiled from a set of 11 surveys at $400 \mathrm{~m}$ line-spacings with a total length of $576,991 \mathrm{~km}$ (see Table 1). These surveys were selected from the Western Australian, Department of Mines and Petroleum MAGIX database ${ }^{1}$ and the data grid is published in Occhipinti et al. (2017).

\section{Results}

We present results for the automated texture segmentation of the regional tilt-derivative of the RTP magnetics over the Earaheedy Basin (see Fig. 8). A log-Gabor filter bank consisting of 6 scales and 6 orientations was used, with successive scales multiplied by a factor of 2.2 and a starting minimum wavelength of 3 cells. A choice of 6 scales was decided upon as this corresponded to a scale of approximately $30 \mathrm{~km}$ (154.6 cells). A Gaussian lowpass filter was used to blur each filter response as suggested by Jain and Farrokhnia, 1991 , where the standard deviation was specified as half the scale wavelength, and the filter size was double the standard deviation. The filter-bank was then clustered using k-means to return a per-pixel classification. Twenty replicates were used in the k-means to avoid any local-minima conver-

\footnotetext{
1 See http://www.dmp.wa.gov.au/Airborne-Geophysics-Index-MAGIX-1557.aspx.
} 


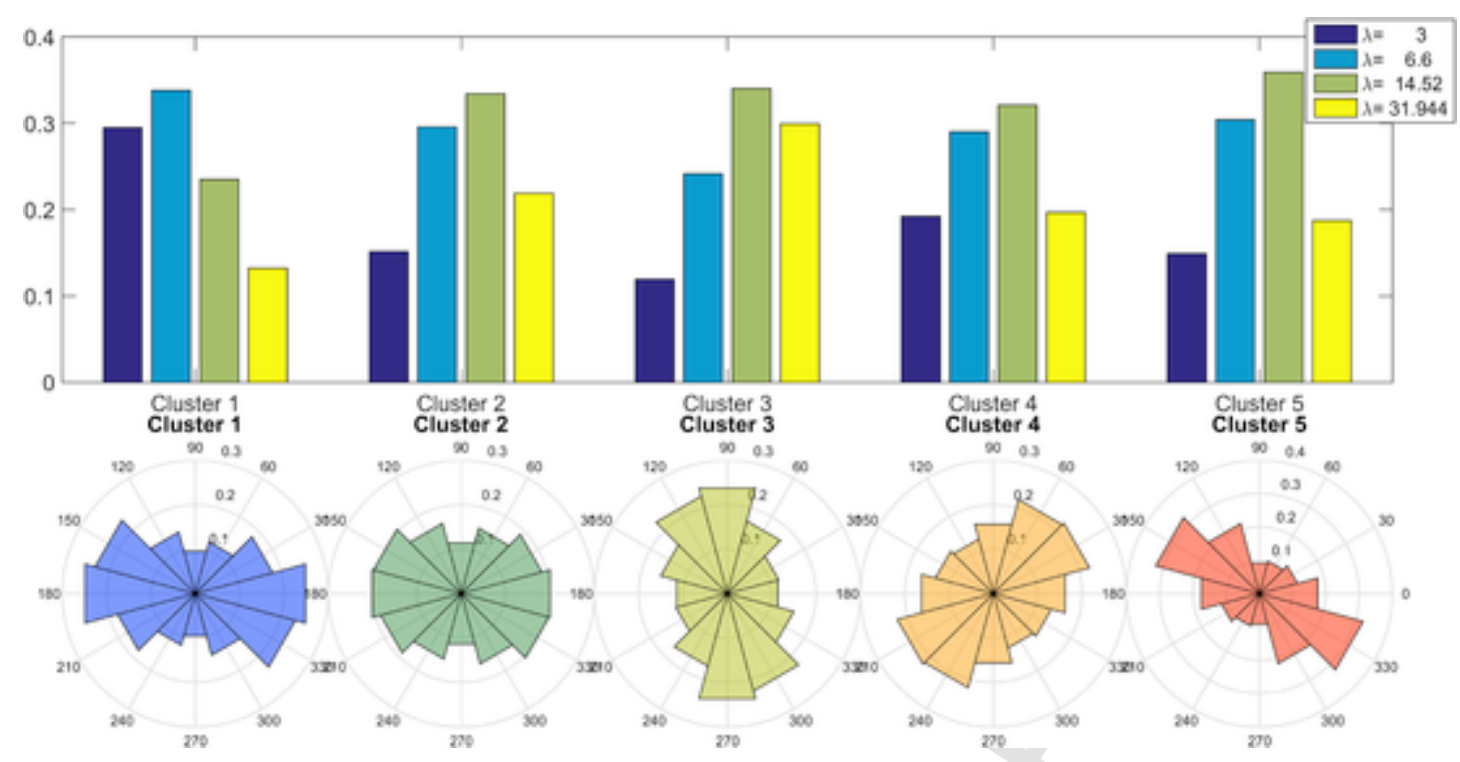

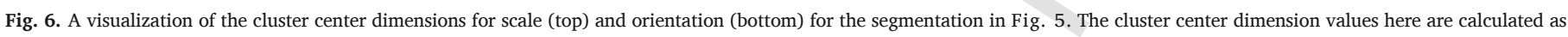
a proportion across all scale dimensions(top) or across all orientation dimensions(bottom).

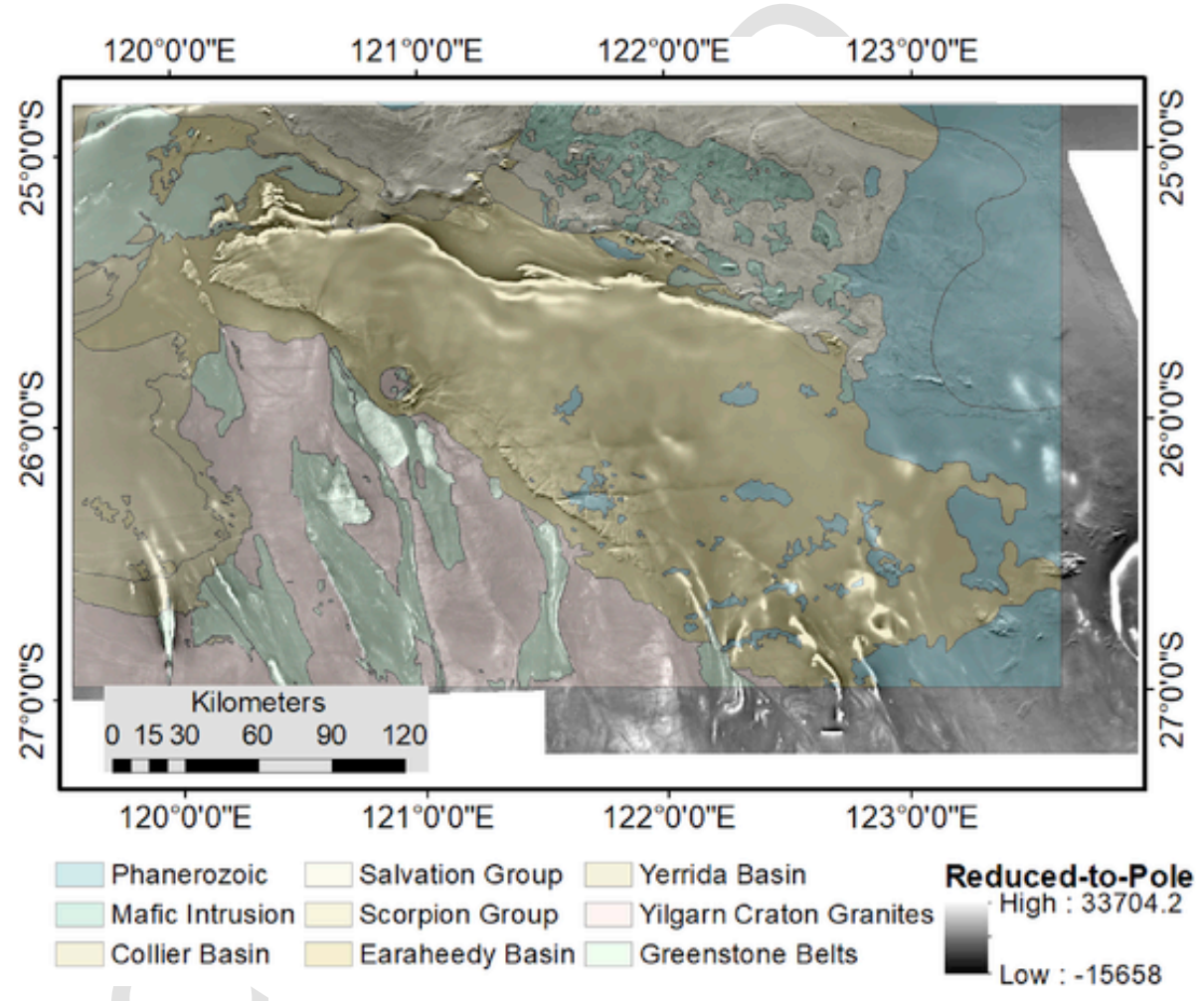

Fig. 7. The compiled Earaheedy reduced-to-pole (RTP) aeromagnetic map overlain by the major tectonic units.

gence. The clustering with the smallest total squared Euclidean distance is then used as the representative segmentation and are presented here as the results. The per-pixel classification output was then smoothed using a mode filter with a window size of 15 .

To validate the automated magnetic texture segmentation results as it relates to the basin stratigraphic architecture, we compare the results to a manual interpretation of the Earaheedy Basin and Archean basement published by Occhipinti et al. (2017) (see Fig. 11). This interpretation combined several streams of data, including outcrop geology, drill core, remote-sensing data (e.g. ASTER), radiometrics and aeromagnetic and gravity data (Occhipinti et al., 2017). As such, although it is geophysically constrained, the results cannot be ex- pected to directly compare with the results from a single dataset. In particular, we cannot expect weakly magnetised units to be differentiated from each other. Nonetheless we expect commonalities with our automated process for those units with strong magnetic character textures, including the Yilgarn Craton granites and greenstones, GIF-dominated Frere Formation and Warakurna Dolerite sills. The presence of weakly-magnetic units, such as the Miningarra Group and Yelma Formation, may then also be inferred from the attenuation of these signals with depth of burial giving an indication of the stratigraphic architecture.

We present the results of the texture domaining using a model of 6 clusters and analyse the geological feasibility of the results by comparing it to the manual geophysically-constrained interpretation. An ini- 


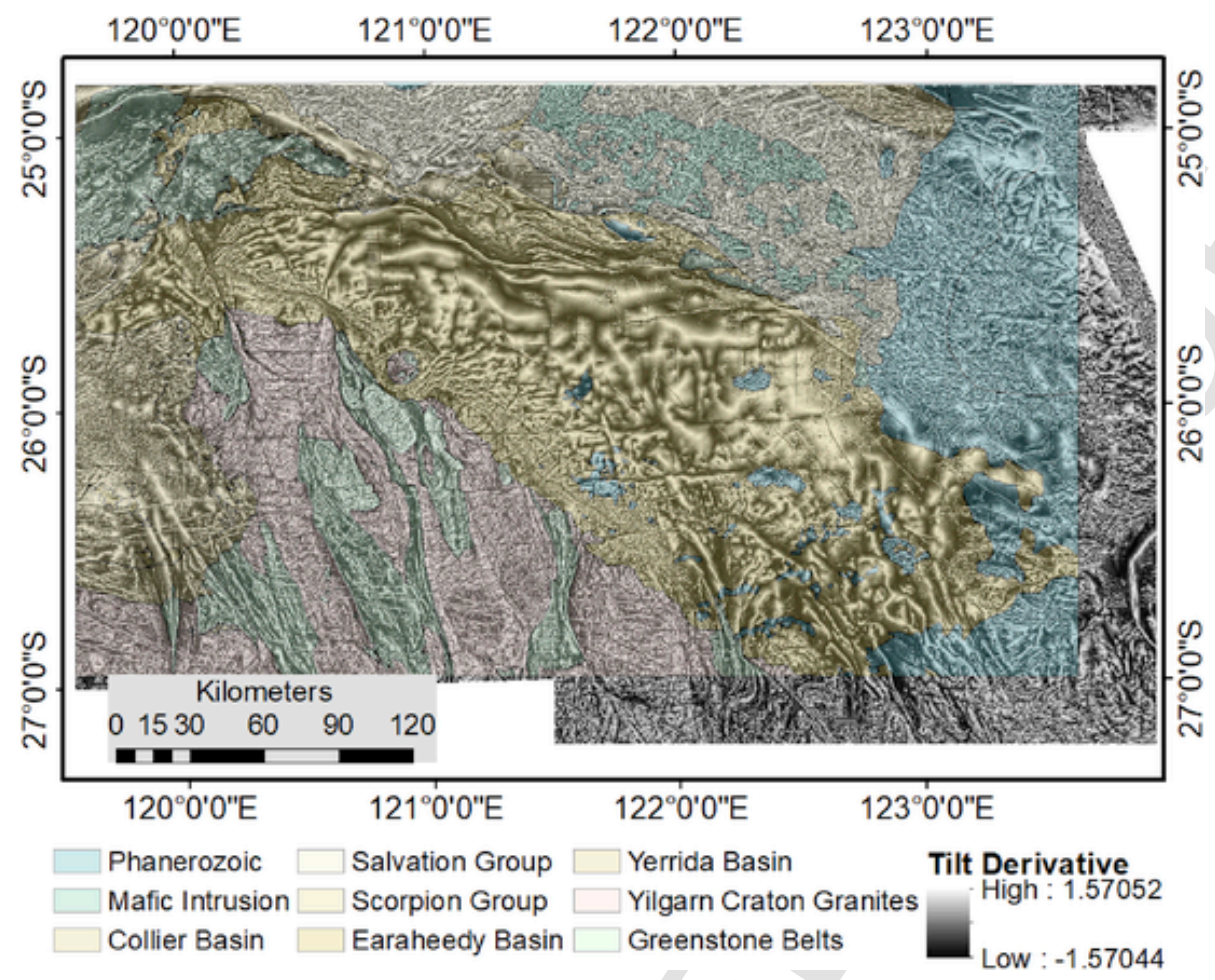

Fig. 8. The tilt angle filter of the reduced-to-pole magnetic map overlain by the major tectonic units.

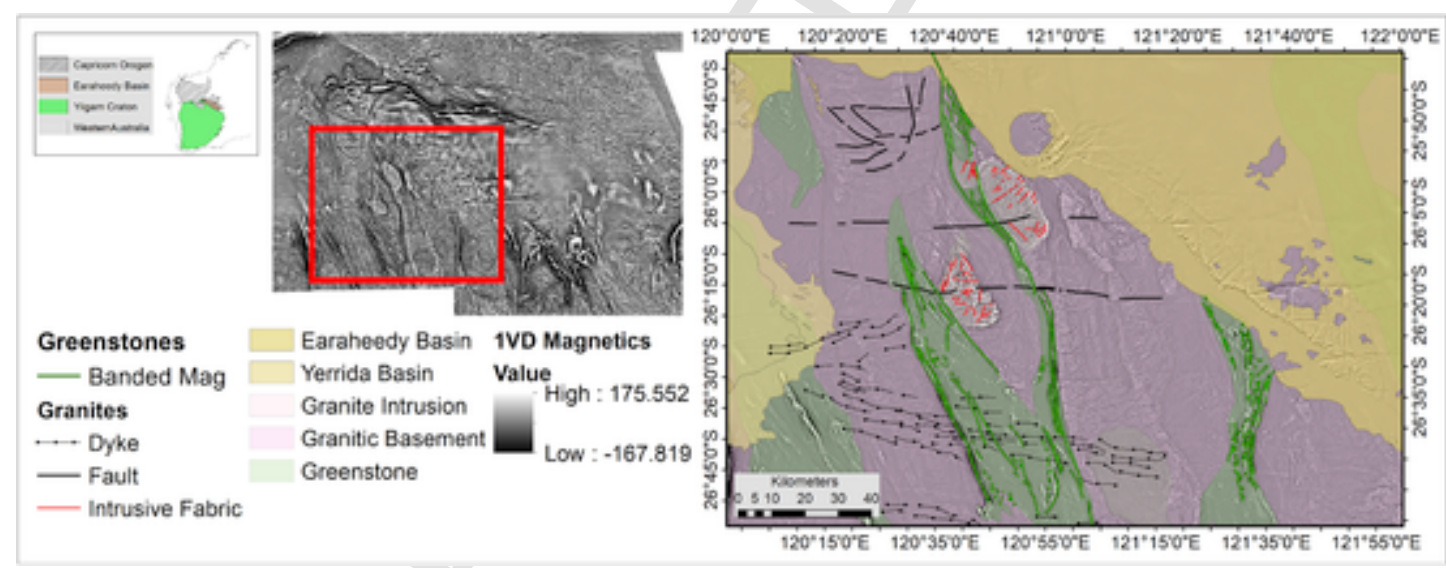

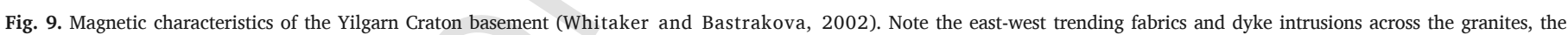
lineated magnetic trends in the greenstone belts.

tial cluster model of 6 regions provides a direct comparison with the major tectonic units in Fig. 11, namely the (1) Greenstone belts and (2) Granites of the Yilgarn Craton, the (3) Yelma and (4) Frere Formations together with the (5) Miningarra Group of the Earaheedy Basin, and the (6) dolerite sill complexes. While non-magnetic units such as the Miningarra Group cannot be directly imaged, the architecture of the basin can be inferred by the attenuation of the magnetic Frere Formation beneath it, which will result in a stronger response in the larger scales of the Gabor filter bank. We then test the stability of our 6 region cluster model against a model with 8 regions.

\subsection{Earaheedy texture domains 6 clusters}

The segments for Cluster 1 and 2 in Fig. 12 correspond well to the granite-greenstones in the Yilgarn craton. Comparing the response distribution in Fig. 12 for Cluster 1 and 2, we can see that orientations are very similar, trending towards the $\mathrm{N}-\mathrm{S}$, but that they are sepa- rated by their scales, with Cluster 2 having more dominate responses in the larger wavelengths. This difference in scale can also be explained by the observation that the Archean greenstone units that correspond to Cluster 2 lie beneath the thicker sediment layer of the Frere Formation in the SE and the Yelma Formation in the NW (Occhipinti et al., 2017).

The Clusters 5 and 6 correspond to the mafic intrusions associated with the Warakuna Large Igneous Province and the Yilgarn granites regions respectively. We can see that the two clusters have similar distributions over scales, but that there is a strong difference in their orientations. Cluster 5 has an almost even distribution over all orientations, which is consistent with how magnetic edges from a sill complex would appear, while Cluster 6 has a strong E-W direction for its dominant orientations.

The separation across the basin between Clusters 2 and 4, and Cluster 3 is well correlated with the Tooloo Group and Miningarra Group respectively. While magnetic sources associated with Cluster 2 

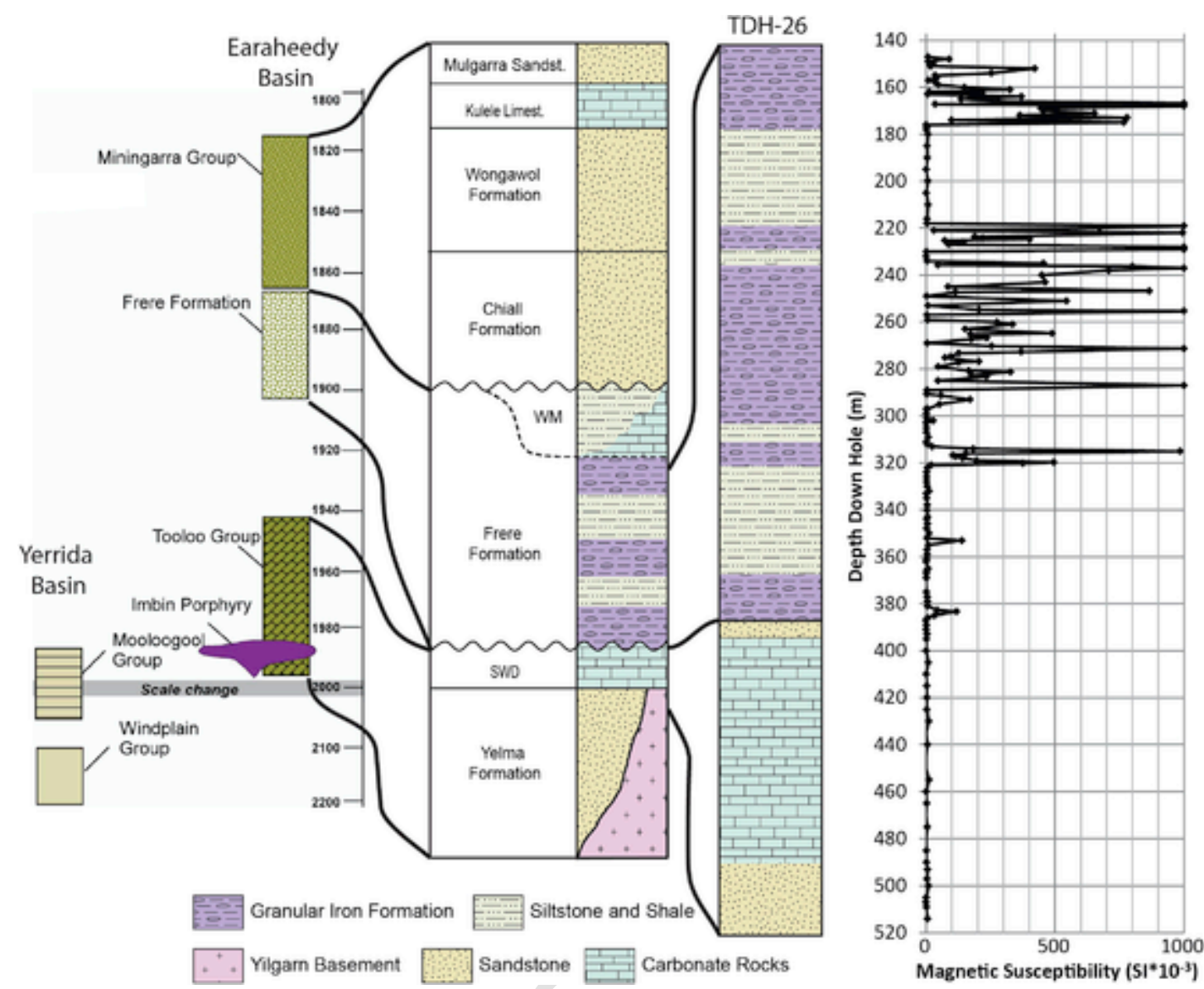

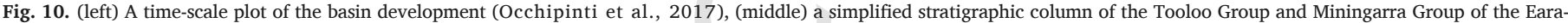
heedy Basin (modified from (Akin et al., 2013)), (right) the magnetic susceptibility along the Frere Formation.

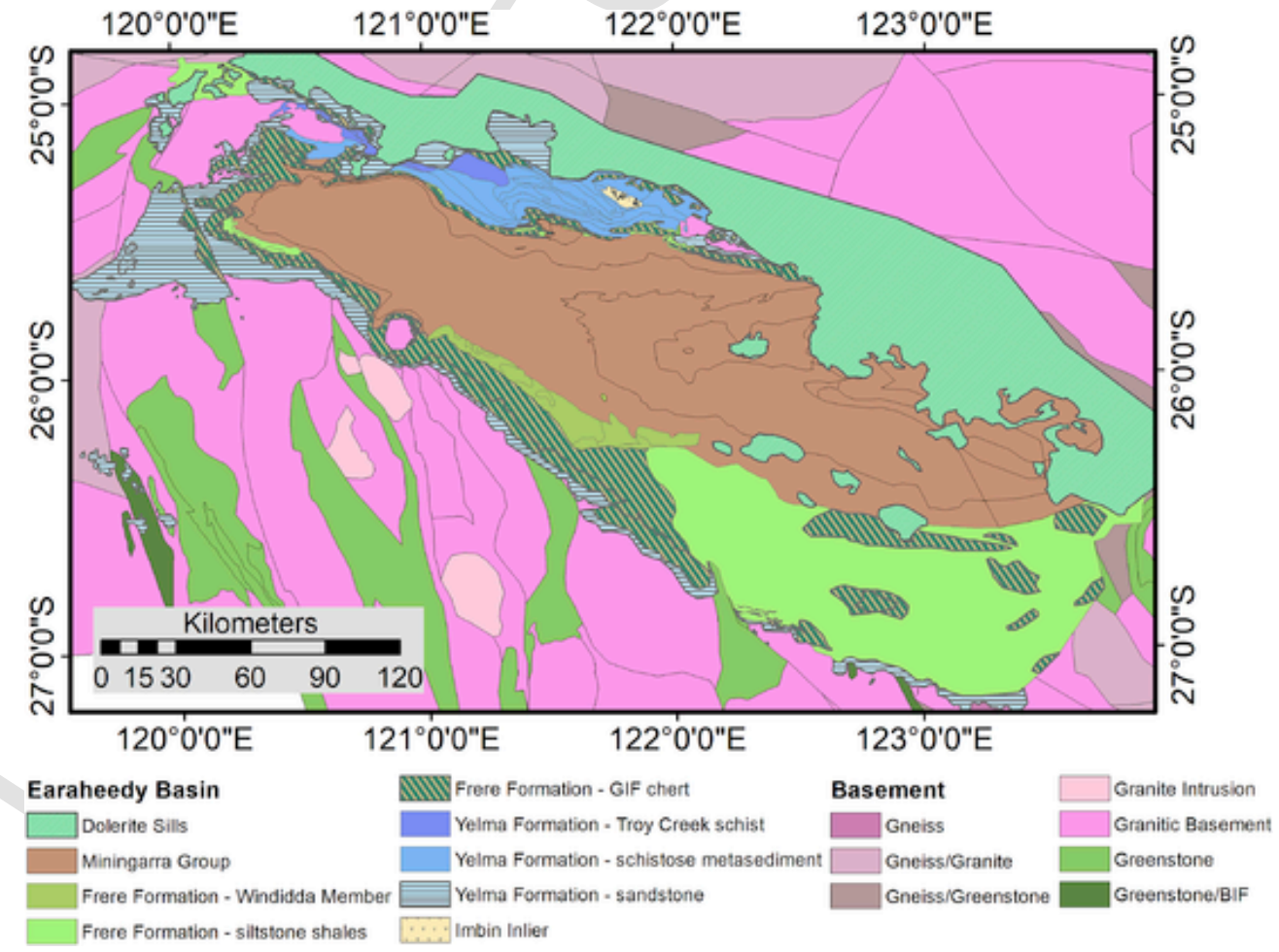

Fig. 11. A geophysically constrained interpretation of the Earaheedy Basin and Archean Basement. 
Table 1

Airborne geophysical surveys chosen from the MAGIX database for the compiled magnetic data grid over the Earaheedy Basin.

\begin{tabular}{|c|c|c|c|c|c|}
\hline MAGIXID & NAME & Line Spacing (m) & Line Direction $\left({ }^{\circ}\right)$ & Total km & Data Link \\
\hline 2266 & Officer Basin p1136 & 400.00 & 180.00 & $105,890.00$ & http://geodownloads.dmp.wa.gov.au/downloads/geophysics/60866.zip \\
\hline 3317 & Madley-Herbert 2010 & 400.00 & 180.00 & $96,088.00$ & http://geodownloads.dmp.wa.gov.au/downloads/geophysics/70465.zip \\
\hline 917 & Glengarry Area A & 400.00 & 90.00 & $21,966.00$ & http://geodownloads.dmp.wa.gov.au/downloads/geophysics/60187.zip \\
\hline 918 & Peak Hill Area B & 400.00 & 180.00 & $53,660.00$ & http://geodownloads.dmp.wa.gov.au/downloads/geophysics/60187.zip \\
\hline 1187 & Bangemalls & 500.00 & 180.00 & $144,700.00$ & http://geodownloads.dmp.wa.gov.au/downloads/geophysics/60192.zip \\
\hline 1081 & Nabberu North & 400.00 & 180.00 & $22,100.00$ & http://geodownloads.dmp.wa.gov.au/downloads/geophysics/60838.zip \\
\hline 1082 & Nabberu South & 400.00 & 90.00 & $22,100.00$ & http://geodownloads.dmp.wa.gov.au/downloads/geophysics/60839.zip \\
\hline 1184 & Kingston & 400.00 & 90.00 & $42,887.00$ & http://geodownloads.dmp.wa.gov.au/downloads/geophysics/60844.zip \\
\hline 1080 & Wiluna & 400.00 & 90.00 & $43,000.00$ & http://geodownloads.dmp.wa.gov.au/downloads/geophysics/60188.zip \\
\hline 1429 & Stanley & 400.00 & 180.00 & $24,600.00$ & http://geodownloads.dmp.wa.gov.au/downloads/geophysics/60200.zip \\
\hline
\end{tabular}

are likely to be the Archean greenstones that are beneath the basin (see Fig. 13), Cluster 4 coincides with much of the magnetic Frere formation - GIF chert in Fig. 11. Moreover, given the similarity in dominant orientations between Clusters 4 and 3 the latter could be interpreted as the Frere Formation underlying the Miningarra Group. The consistency of the scale and orientation to the southern and western parts of the Basin show reliability of the segmentation, but the repetition of Cluster 2 and 5 in the northern parts, which are deformed through the Stanley Fold Belt, show some of the limitations of the segmentation when there is no spatial consideration.

\subsection{Earaheedy texture domains 8 clusters}

The results as presented in Fig. 14 show how by increasing the number of clusters from 6 to 8 in the model certain clusters are preserved while others are separated. Clusters 1, 2 and 3, which correspond respectively to the Archean Greenstones, Archean Greenstones undercover and buried Frere Formation, are spatially like the K6 Domains with the cluster centers similar.

The Cluster 4 from the K6 Domains has separated into the two clusters 4 and 5 in K8, with the difference in orientation being dominant in the cluster centers. Cluster 4 and 5 in Fig. 14 show a separation between the exposed Frere Formation-GIF and the metasedimentary rocks of the Stanley Fold Belt. The strong E-W dominance of the orientation in Cluster 5 is consistent with the region of the Stanley Fold belt. The Clusters 5 and 6 in the K6 domains have split across Clusters 6, 7 and 8 in the K8 domains. While Cluster 5 in the K6 domains has an even distribution across all orientations, the dolerite sills in Clusters 6 for K8 have a more dominant $\mathrm{E}-\mathrm{W}$ trend compared to the more even distribution in Cluster 8 (see Fig. 15). While Cluster 8 does not exhibit a dominant orientation, the scale distribution when compared to Cluster 6 in the K6 domains, show that it has a larger scale response. This separation of the Granites in Clusters 7 and 8 shows that the difference in dominant scale can be attributed to differences in the amount of fracturing.

\section{Conclusion and future work}

We have presented a method to automatically characterize the sedimentary Earaheedy Basin and surrounding basement using only the texture of the aeromagnetics of the area. By computing texture as a multi-scale, orientation-dependent feature, we show how amplitude-normalized RTP magnetics (potential-field tilt), separate into geologically meaningful domains. This is also demonstrated by comparing the distribution of filter-responses across scales and orientations for different domains.

While any integration of aeromagnetic domains into a geological interpretation requires careful consideration of other geological data, our automated domaining method provides a repeatable and testable means of assessing the data and can be performed to assist interpreta- tion. By comparing the results from the automated domaining using different numbers of clusters, areas of complexity which may result in higher uncertainty can be identified beforehand. Automated methods also provide a means of assessing how a geophysical dataset is connected to a pre-existing map. An example of this could be comparing legacy geologic maps to the automated texture domains from different geophysical datasets. This can be used as a measure of the value of different geophysical datasets, which can be used to further assist the decision of which datasets should be collected in an exploration campaigns. Another application is the integration of automated domains to lithoclassification. Current approaches to lithoclassification from geophysical and remote-sensing data do not incorporate scale and orientation as input features (Cracknell and Reading, 2013; Kuhn et al., 2018), which we have demonstrated to be a valuable source of information. This is an area we intend to consider for future work as we show that automated texture domains can be used to improve and refine automated classification for geological mapping.

Another limitation that is necessary to consider is how deformation and topography can affect localized texture. Secondary magnetite and maghematite that is produced during alteration, or weathering can significantly increase the magnetic susceptibility properties of sediments and metasediments (Grant, 1985), and thus produce distinct patterns that are unrelated to deposition or emplacement. An example of this can be observed when comparing the domains in K6 and K8 (Figs. 12 and 14) in the NW margin of the Earaheedy that is affected by the Stanley Fold Belt (Figs. 13 and 15). The orientation of the metamorphosed Yelma formation and Frere Formation units are smoothly varying but there is no single dominant orientation. This can be interpreted to be a result of the sinistral strike-slip deformation adjacent to the Yilgarn-Pilbara cratonic boundary during the folding of the Earaheedy (Williams et al., 2004). In addition, the tectonic reworking of the usually non-magnetic Yelma Formation has developed some magnetization that generates some similarities to the Frere magnetic units. Without some prior constraints on how orientations are grouped, i.e. the sinistral direction of the regional deformation to group orientations (Kass and Witkin, 1987), or by integration with additional datasets, grouping individual pixels would be problematic. Other possible applications include the identification of distinct patterns of magnetic anomalies in TMI grids that are a result of the development of surficial maghemite on weathered laterite profiles (Isles and Rankin, 2013). This can be used in identifying palaeo-surfaces and palaeo-drainage systems that are important for targeting placer deposit mineralization (Anand and Butt, 2010). The current approaches for modeling prospective palaeochannels for these surficial mineral systems from remote sensing and satellite data utilise radiometric, ASTER, surface geochemical maps and digital elevation models as input data (Porwal et al., 2015), but in general do not use magnetic data grids as spatial proxies. This limits the ability of these prospectivity models being applied under cover which we see as a promising possible application 

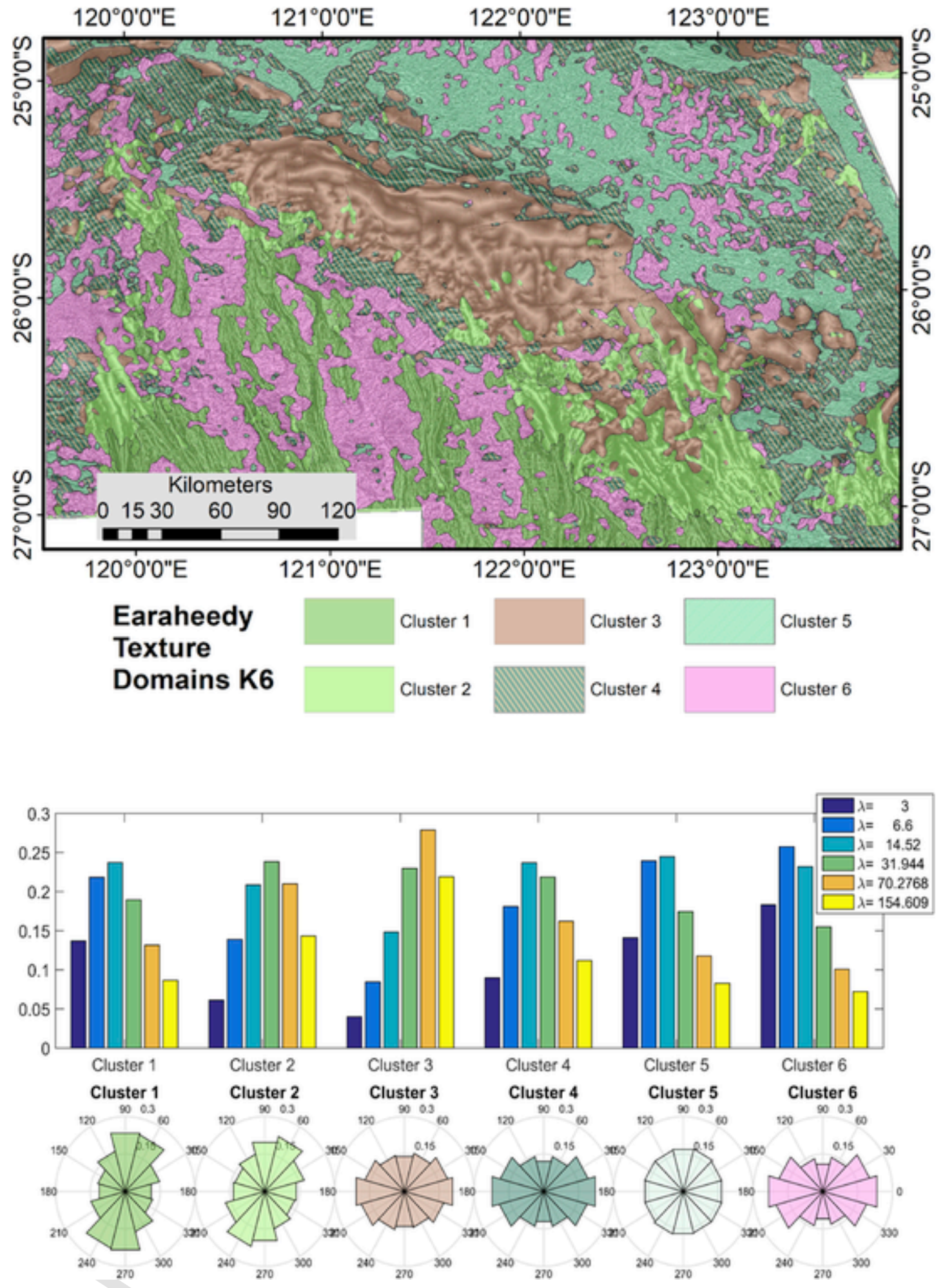

Fig. 12. The 6 cluster model texture domains and tilt-derivate of the RTP aeromagnetic map (top), the texture domain characteristics by scale and orientation (bottom).

of automated aeromagnetic data grid texture domaining. We intend to further develop and apply our methods for these other types of geological settings.

\section{Computer code availability}

This technique has been implemented in the freely available Integrated Exploration Platform (https://www.waexplorationplatform.wa. edu.au/). This software is provided as a software plugin for ArcMap and MapInfo Pro. The Integrated Exploration Platform is a product of GSWA. MATLAB implementations of Gabor filter construction can be found at https://www.peterkovesi.com/matlabfns/. 


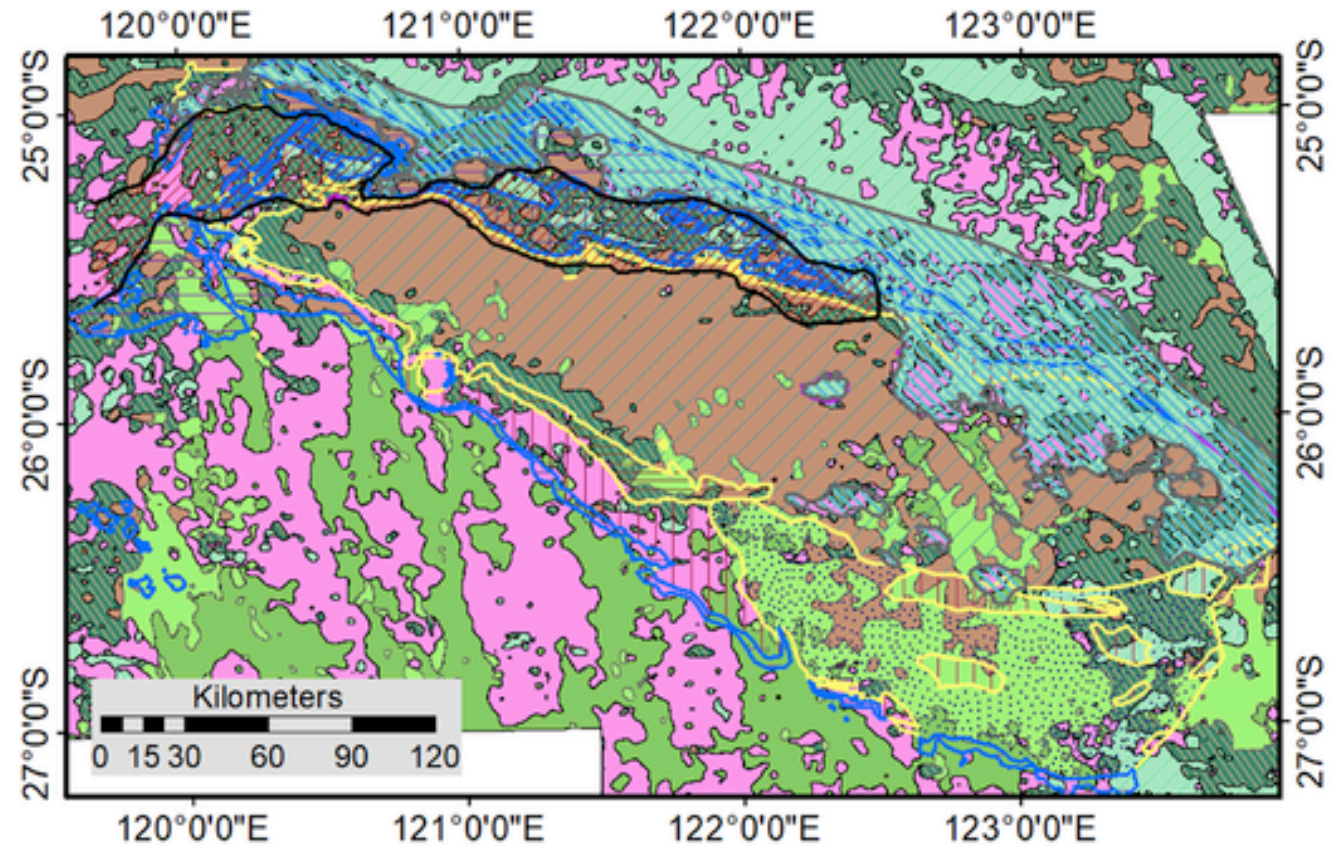

\begin{tabular}{|c|c|}
\hline Yelma Formation - sandstone & Frere Formation - siltstone shales \\
\hline Zyelma Formation - schistose metasediment & Erere Formation - Windidda Member \\
\hline QYelma Formation - Troy Creek schist & Frere Formation - GIF chert \\
\hline
\end{tabular}

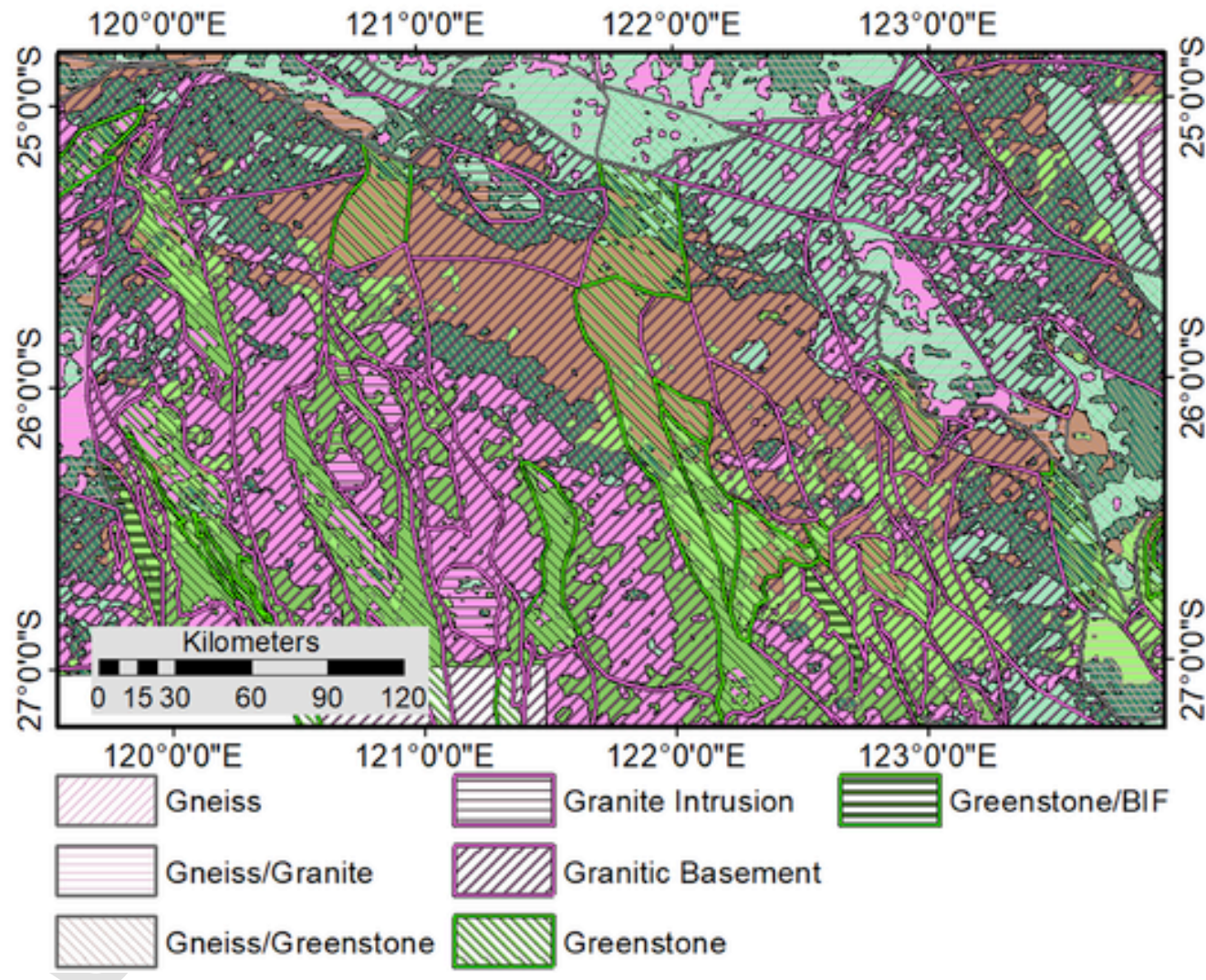

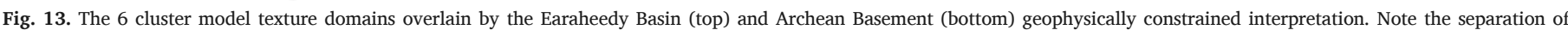
Greenstones beneath the Earaheedy and the disjoint segmentation across the Stanley Fold Belt. 

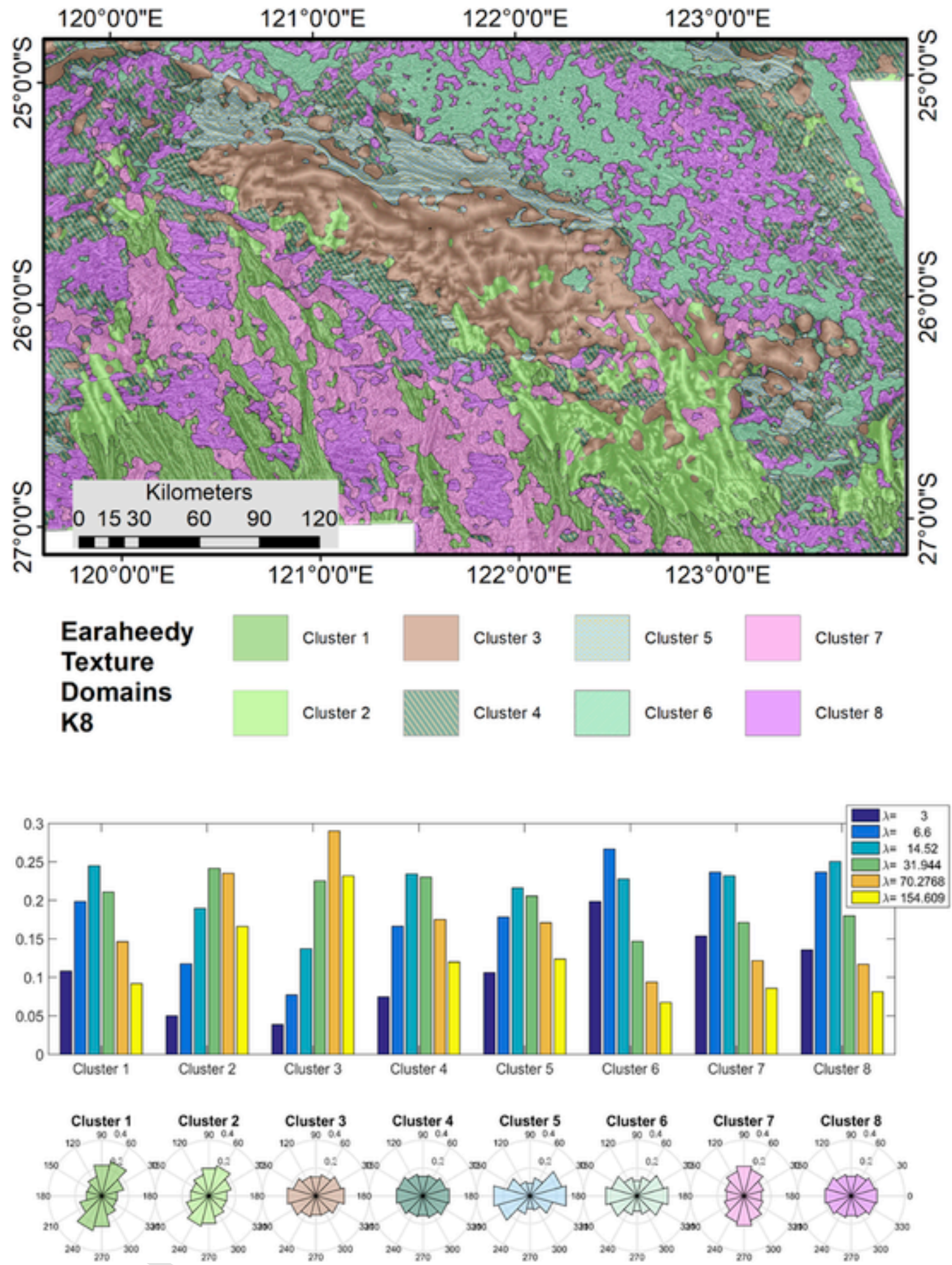

Fig. 14. The 8 cluster model texture domains and tilt-derivate of the RTP aeromagnetic map (top), the texture domain characteristics by scale and orientation (bottom).

\section{Acknowledgements}

This work was financially supported by Geological Survey of Western Australia (GSWA) in the Royalties for Region Exploration Incentive Scheme, and Australian Research Council Linkage LP140100267. We acknowledge the scientific contribution of Peter Kovesi, Mark Jessell and Mike Dentith, and thank the support of Ian Tyler and Ruth Murdie from GSWA.

\section{Appendix A. Supplementary data}

Supplementary data to this article can be found online at https://doi. org/10.1016/j.cageo.2019.104396. 


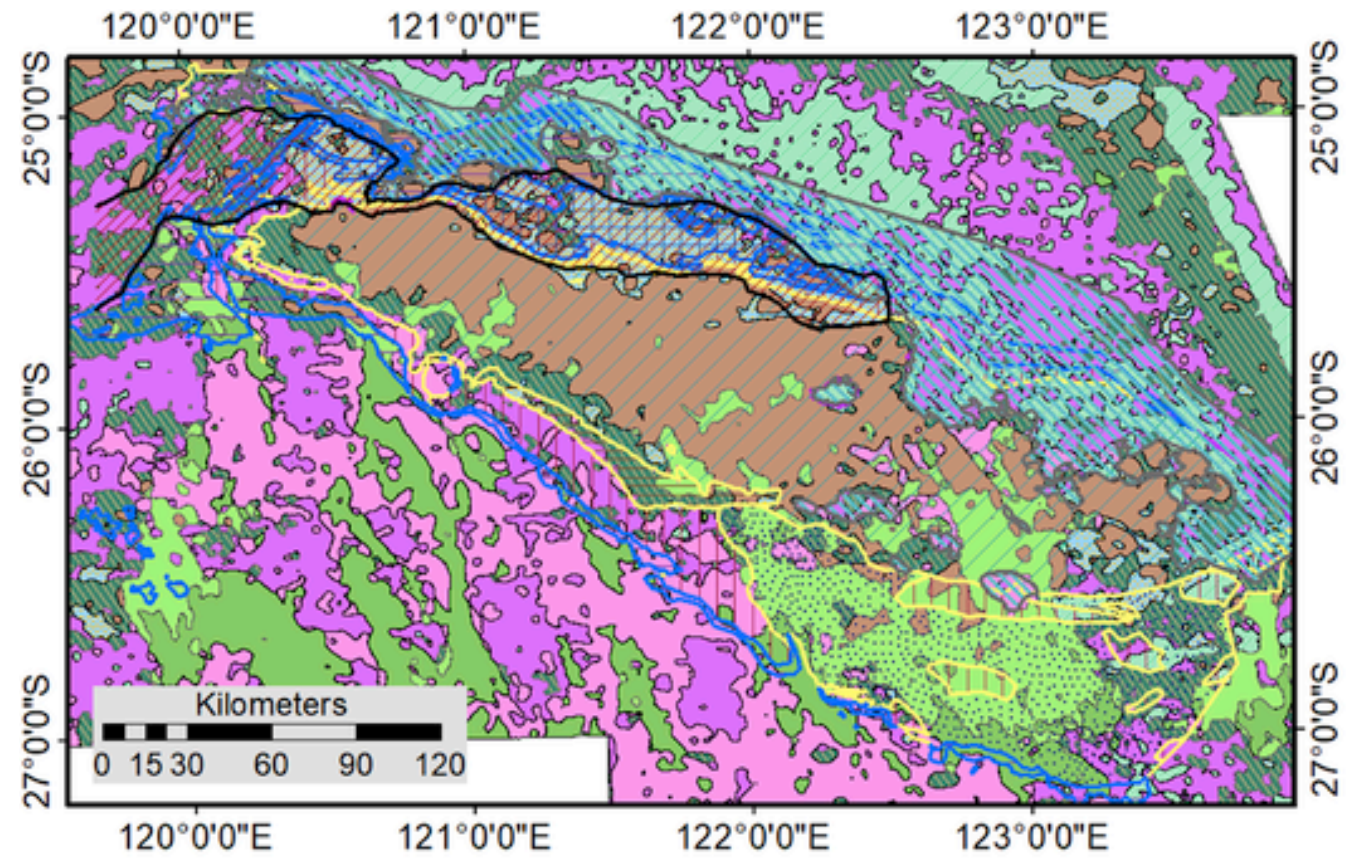

\begin{tabular}{|c|c|c|}
\hline Jyelma Formation - sandstone & Fy Frere Formation - siltstone shales & Miningarra Group \\
\hline Yelma Formation - schistose metasediment & Frere Formation - Windidda Member & Jsills \\
\hline QX Yelma Formation - Troy Creek schist & Frere Formation - GIF chert & Stanley Fold Belt \\
\hline
\end{tabular}

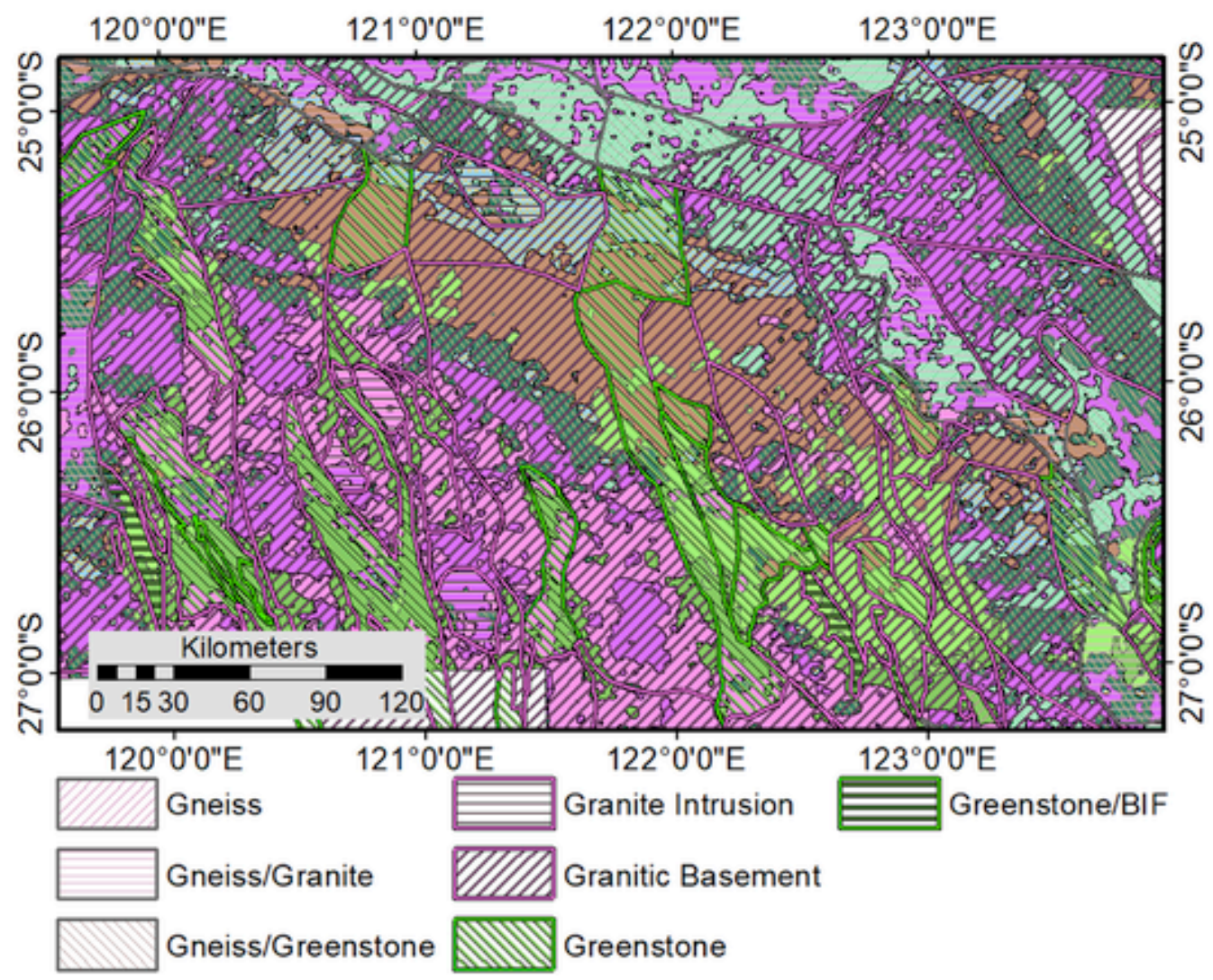

Fig. 15. The 8 cluster model texture domains overlain by the Earaheedy Basin (top) and Archean Basement (bottom) geophysically constrained interpretation. Note the separation of the Granitic Basement into different fracture zones and the improved segmentation of the Stanley Fold Belt. 


\section{References}

Aitken, A.R.A., Betts, P.G., 2009. Multi-scale integrated structural and aeromagnetic analysis to guide tectonic models: an example from the eastern Musgrave Province, Central Australia. Tectonophysics 476, 418-435. doi:10.1016/j.tecto.2009.07.007.

Aitken, A.R.A., Betts, P.G., Schaefer, B.F., Rye, S.E., 2008. Assessing uncertainty in the integration of aeromagnetic data and structural observations in the Deering Hills region of the Musgrave Province. Aust. J. Earth Sci. 55, 1127-1138. doi:10.1080/ 08120090802266600 .

Aitken, A.R.A., Holden, E.-J., Dentith, M.C., 2013. Semiautomated quantification of the influence of data richness on confidence in the geologic interpretation of aeromagnetic maps. Geophysics 78, J1-J13. doi:10.1190/geo2012-0033.1.

Akin, S.J., Pufahl, P.K., Hiatt, E.E., Pirajno, F., 2013. Oxygenation of shallow marine environments and chemical sedimentation in Palaeoproterozoic peritidal settings: Frere Formation, Western Australia. Sedimentology 60, 1559-1582. doi:10.1111/ sed.12038.

Anand, R.R., Butt, C.R.M., 2010. A guide for mineral exploration through the regolith in the Yilgarn Craton, Western Australia. Aust. J. Earth Sci. 57, 1015-1114. doi:10.1080/ 08120099.2010 .522823 .

Austin, J.R., Schmid, S., Foss, C.A., 2017. Using stratiform magnetic anomalies to map near-surface architecture: insights from the Amadeus Basin. Aust. J. Earth Sci. 64, 353-383. doi:10.1080/08120099.2017.1290683.

Balsley, J.R., 1952. Aeromagnetic surveying. In: Landsberg, H.E. (Ed.), Advances in Geophysics. Elsevier, pp. 313-349.

Blakely, R.J., Simpson, R.W., 1986. Approximating edges of source bodies from magnetic or gravity anomalies. Geophysics 51, 1494-1498. doi:10.1190/1.1442197.

Blaschke, T., 2010. Object based image analysis for remote sensing. ISPRS J. Photogrammetry Remote Sens. 65, 2-16. doi:10.1016/j.isprsjprs.2009.06.004.

Bourne, B.T., Trench, A., Dentith, M.C., Ridley, J., 1993. Physical property variations within archaean granite-greenstone terrane of the Yilgarn Craton, Western Australia: the influence of metamorphic grade. Explor. Geophys. 24, 367-374. doi:10.1071/ eg993367.

Bovik, A.C., Clark, M., Geisler, W.S., 1990. Multichannel texture analysis using localized spatial filters. IEEE Trans. Pattern Anal. Mach. Intell. 12, 55-73. doi:10.1109/ 34.41384.

Clark, D.A., Emerson, D.W., 1991. Notes on rock magnetization characteristics in applied geophysical studies. Explor. Geophys. 22, 547-555. doi:10.1071/eg991547.

Cooper, G.R.J., 2004. The textural analysis of gravity data using co-occurrence matrices. Comput. Geosci. 30, 107-115. doi:10.1016/j.cageo.2003.08.001.

Cooper, G.R.J., 2009. The antialiased textural analysis of aeromagnetic data. Comput. Geosci. 35, 586-591. doi:10.1016/j.cageo.2008.04.009.

Cooper, G.R.J., Cowan, D.R., 2005. The use of textural analysis to locate features in geophysical data. Comput. Geosci. 31, 882-890. doi:10.1016/j.cageo.2005.02.001.

Cordell, L., Grauch, V., 1985. Mapping basement magnetization zones from aeromagnetic data in the san Juan basin, New Mexico. In: Hinze, W.J. (Ed.), The Utility of Regional Gravity and Magnetic Anomaly Maps. Society of Exploration Geophysicists, pp. 181-197.

Cracknell, M.J., Reading, A.M., 2013. The upside of uncertainty: identification of lithology contact zones from airborne geophysics and satellite data using random forests and support vector machines. Geophysics 78, WB113-WB126. doi:10.1190/ geo2012-0411.1.

Cracknell, M.J., Reading, A.M., 2014. Geological mapping using remote sensing data: a comparison of five machine learning algorithms, their response to variations in the spatial distribution of training data and the use of explicit spatial information. Comput. Geosci. 63, 22-33. doi:10.1016/j.cageo.2013.10.008.

Cross, G.R., Jain, A.K., 1983. Markov random field texture models. IEEE Trans. Pattern Anal. Mach. Intell. PAMI 5, 25-39. doi:10.1109/TPAMI.1983.4767341.

Daugman, J.G., 1985. Uncertainty relation for resolution in space, spatial frequency, and orientation optimized by two-dimensional visual cortical filters. JOSA A 2, 1160-1169. doi:10.1364/JOSAA.2.001160.

De Valois, R.L., Albrecht, D.G., Thorell, L.G., 1982. Spatial frequency selectivity of cells in macaque visual cortex. Vision Res. 22, 545-559. doi:10.1016/0042-6989(82)90113-4.

De Valois, R.L., William Yund, E., Hepler, N., 1982. The orientation and direction selectivity of cells in macaque visual cortex. Vision Res. 22, 531-544. doi:10.1016/ 0042-6989(82)90112-2.

Dentith, M. 1995. Textural filtering of aeromagnetic data. Explor. Geophys. 26, 209-214.

Dentith, M., Cowan, D., 2011. Using potential field data for petroleum exploration targeting, Amadeus Basin, Australia. Explor. Geophys. 42, 190-198. doi:10.1071/EG10018.

Dentith, M., Cowan, D.R., Tompkins, L.A., 2000. Enhancement of subtle features in aeromagnetic data. Explor. Geophys. 31, 104-108. doi:10.1071/EG00104.

Dentith, M.C., 2014. Geophysics for the Mineral Exploration Geoscientist. Cambridge University Press, Cambridge. (Michael C.)

Dhu, T., Dentith, M., Hillis, R.R., 2000. Enhancement of airborne magnetic data using the variation method of fractal dimension estimation. Explor. Geophys. 31, 58-65.

Dhu, T., Dentith, M.C., Hillis, R.R., 1999. The use of fractal dimension estimators for enhancing airborne magnetic data. Explor. Geophys. 30, 333-337. doi:10.1071/ EG999033.

Dunlop, D.J., 1997. Rock Magnetism Fundamentals and Frontiers. Cambridge University Press, Cambridge.

Field, D.J., 1987. Relations between the statistics of natural images and the response properties of cortical cells. JOSA A 4, 2379-2394. doi:10.1364/JOSAA.4.002379.

Fischer, S., Šroubek, F., Perrinet, L., Redondo, R., Cristóbal, G., 2007. Self-invertible 2D log-Gabor wavelets. Int. J. Comput. Vis. 75, 231-246. doi:10.1007/ s11263-006-0026-8.
Gabor, D., 1946. Theory of communication. Part 1: the analysis of information. J. Inst. Eng. Electron. Part III Radio Commun. Eng. 93, 429-441. doi:10.1049/ji-3-2.1946.0074.

Geological Survey of Western Australia Geological Survey of Western Australia, 2017. In 1: 500000 Tectonic Units of Western Australia, 2017.

Grant, F.S., 1985. Aeromagnetics, geology and ore environments, I. Magnetite in igneous, sedimentary and metamorphic rocks: an overview. Geoexploration 23, 303-333. doi:10.1016/0016-7142(85)90001-8.

Gunn, P., Maidment, D., Milligan, P., 1995. Interpreting aeromagnetic data in areas of limited outcrop: an example from the Arunta Block, Northern Territory. Explor. Geophys. 26, 227-232. doi:10.1071/EG995227.

Gunn, P.J., 1997. Application of aeromagnetic surveys to sedimentary basin studies. AGSO J. Aust. Geol. Geophys. 17, 133-144.

Haralick, R.M., 1979. Statistical and structural approaches to texture. Proc. IEEE 67, 786-804 doi:10.1109/PROC.1979.11328.

Holden, E.-J., Dentith, M., Kovesi, P., 2008. Towards the automated analysis of regiona aeromagnetic data to identify regions prospective for gold deposits. Comput. Geosci. 34, 1505-1513. doi:10.1016/j.cageo.2007.08.007.

Holden, E.-J., Wong, J.C., Kovesi, P., Wedge, D., Dentith, M., Bagas, L., 2012. Identifying structural complexity in aeromagnetic data: an image analysis approach to greenfields gold exploration. Ore Geol. Rev. 46, 47-59. doi:10.1016/j.oregeorev.2011.11.002.

Holden, E.-J., Wong, J.C., Wedge, D., Martis, M., Lindsay, M., Gessner, K., 2016. Improving assessment of geological structure interpretation of magnetic data: an advanced data analytics approach. Comput. Geosci. 87, 101-111. doi:10.1016/j.cageo.2015.11.010.

Hubel, D.H., Wiesel, T.N., 1962. Receptive fields, binocular interaction and functiona architecture in the cat's visual cortex. J. Physiol. 160, 106-154. doi:10.1113/ jphysiol.1962.sp006837.

Isles, D.J., Rankin, L.R., 2013. Geological Interpretation of Aeromagnetic Data.

Jain, A.K., Farrokhnia, F., 1991. Unsupervised texture segmentation using Gabor filters. Pattern Recognit. 24, 1167-1186. doi:10.1016/0031-3203(91)90143-S.

Kass, M., Witkin, A., 1987. Analyzing oriented patterns. Comput. Vis. Graph Image Process 37, 362-385. doi:10.1016/0734-189X(87)90043-0.

Kovesi, P., 1999. Image features from phase congruency. Videre A J. Comput. Vis. Res. 1, $1-26$.

Kuhn, S., Cracknell, M.J., Reading, A.M., 2018. Lithologic mapping using Random Forests applied to geophysical and remote-sensing data: a demonstration study from the Eastern Goldfields of AustraliaLithologic mapping with RF. Geophysics 83, B183-B193. doi:10.1190/geo2017-0590.1.

Landy, M.S., 2013. Texture analysis and perception. In: The New Visual Neurosciences. MIT Press, Cambridge, MA, USA, pp. 639-652.

Lindeberg, T., 1994. Scale-space theory: a basic tool for analyzing structures at differen scales. J. Appl. Stat. 21, 225-270. doi:10.1080/757582976.

Lloyd, S., 1982. Least squares quantization in PCM. IEEE Trans. Inf. Theory 28, 129-137. doi:10.1109/TIT.1982.1056489.

Masoumi, F., Eslamkish, T., Abkar, A.A., Honarmand, M., Harris, J.R., 2017. Integration of spectral, thermal, and textural features of ASTER data using Random Forests classification for lithological mapping. J. Afr. Earth Sci. 129, 445-457. doi:10.1016/ j.jafrearsci.2017.01.028

Miller, H.G., Singh, V., 1994. Potential field tilt-a new concept for location of potentia field sources. J. Appl. Geophys. 32, 213-217. doi:10.1016/0926-9851(94)90022-1.

Morris, P.A., Pirajno, F., 2005. Mesoproterozoic sill complexes in the Bangemall Supergroup, Western Australia. Geology, geochemistry and mineralization potential. Geol. Surv. West. Aust.

Morris, P.A., Pirajno, F., Shevchenko, S., 2003. Proterozoic mineralization identified by in tegrated regional regolith geochemistry, geophysics and bedrock mapping in Western Australia Geochem. Explor. Environ. Anal. 3, 13-28. doi:10.1144/1467-787302-041.

Nabighian, M.N., 1984. Toward a three-dimensional automatic interpretation of potentia field data via generalized Hilbert transforms; fundamental relations. Geophysics 49 780-786. doi:10.1190/1.1441706.

Nabighian, M.N., Grauch, V.J.S., Hansen, R.O., LaFehr, T.R., Li, Y., Peirce, J.W., Phillips, J.D., Ruder, M.E., 2005. The historical development of the magnetic method in exploration. Geophysics 70, 33ND-61ND. doi:10.1190/1.2133784.

Nava, R., Escalante-Ramírez, B., Cristóbal, G., 2011. A comparison study of Gabor and log-Gabor wavelets for texture segmentation. In: 2011 7th International Symposium on Image and Signal Processing and Analysis (ISPA). pp. 189-194.

Occhipinti, S., Hocking, R., Lindsay, M., Aitken, A., Copp, I., Jones, J., Sheppard, S, Pirajno, F., Metelka, V., 2017. Paleoproterozoic Basin development on the northern Yilgarn Craton, western Australia. Precambrian Res. 300, 121-140. doi:10.1016/ j.precamres.2017.08.003

Olaniyan, O., Smith, R.S., Morris, B., 2013. Qualitative geophysical interpretation of the sudbury Structure Interpretation of the sudbury structure. Interpretation 1, T25-T43. doi:10.1190/INT-2012-0010.1

Petrou, M., García Sevilla, P., 2006. Image Processing: Dealing with Texture. John Wiley \& Sons, Ltd.

Pilkington, M., 1998. Magnetisation mapping in rugged terrain. Explor. Geophys. 29, 560-564. doi:10.1071/eg998560.

Pilkington, M., Keating, P., 2004. Contact mapping from gridded magnetic data - a comparison of techniques. Explor. Geophys. 35, 306-311. doi:10.1071/EG04306

Pilkington, M., Tschirhart, V., 2017. Practical considerations in the use of edge detectors for geologic mapping using magnetic data. Geophysics 82, J1-J8. doi:10.1190/ geo2016-0364.1

Pirajno, F., Hocking, R.M., Reddy, S.M., Jones, A.J., 2009. A review of the geology and geodynamic evolution of the Palaeoproterozoic Earaheedy Basin, Western Australia. Earth Sci. Rev. 94, 39-77. doi:10.1016/j.earscirev.2009.03.003.

Porwal, A., Das, R.D., Chaudhary, B., Gonzalez-Alvarez, I., Kreuzer, O., 2015. Fuzzy inference systems for prospectivity modeling of mineral systems and a case-study 
for prospectivity mapping of surficial Uranium in Yeelirrie Area, Western Australia. Ore Geol. Rev. 71, 839-852. doi:10.1016/j.oregeorev.2014.10.016.

Randen, T., Husoy, J.H., 1999. Filtering for texture classification: a comparative study. IEEE Trans. Pattern Anal. Mach. Intell. 21, 291-310. doi:10.1109/34.761261.

Rasmussen, B., Fletcher, I.R., Bekker, A., Muhling, J.R., Gregory, C.J., Thorne, A.M., 2012. Deposition of 1.88-billion-year-old iron formations as a consequence of rapid crustal growth. Nature 484, 498-501. doi:10.1038/nature11021.

Reynolds, R.L., Rosenbaum, J.G., Hudson, M., Fishman, N., 1990. Rock magnetism, the distribution of magnetic minerals in the Earth's crust, and aeromagnetic anomalies. U. S. Geol. Surv. Bull. 1924, 24-45.

Sertcelik, I., Kafadar, O., Kurtulus, C., 2013. Use of the two dimensional Gabor filter to interpret magnetic data over the Marmara sea, Turkey. Pure Appl. Geophys. 170, 887-894. doi:10.1007/s00024-012-0587-0.

Shankar, V., Rodriguez, J.J., Gettings, M.E., 2006. Texture analysis for automated classification of geologic structures. In: 2006 IEEE Southwest Symposium on Image Analysis and Interpretation. pp. 81-85.

Shevchenko, S.I., 2000. Gravity Data -- Kingston and Stanley 1:250 000 Sheets, Western Australia. Geological Survey of Western Australia, Perth, Western Australia.

Singhroy, V.H., Pilkington, M., 2014. Geological mapping using earth's magnetic field. In: Njoku, E.G. (Ed.), Encyclopedia of Remote Sensing. Springer New York, New York, NY, pp. 232-237.

Steenland, N.C., 1963. An evaluation of the peace river aeromagnetic interpretation. Geophysics 28, 745-755. doi:10.1190/1.1439266.

Tschirhart, P., Morris, B., 2015. Improved edge detection mapping through stacking and integration: a case study in the Bathurst Mining Camp. Geophys. Prospect. 63, 283-295. doi:10.1111/1365-2478.12188.

Tuceryan, M., Jain, A.K., 1990. Texture segmentation using Voronoi polygons. IEEE Trans. Pattern Anal. Mach. Intell. 12, 211-216. doi:10.1109/34.44407.
Tuceryan, M., Jain, A.K., 1999. Texture analysis. In: Handbook of Pattern Recognition and Computer Vision. WORLD SCIENTIFIC, pp. 207-248.

Uieda, L., Oliveira, V.C., Jr., Barbosa, V.C., 2013. Modeling the earth with fatiando a terra. In: Presented at the Proceedings of the 12th Python in Science Conference (SciPy 2013).

Wallis, T.S.A., Funke, C.M., Ecker, A.S., Gatys, L.A., Wichmann, F.A., Bethge, M., 2017. A parametric texture model based on deep convolutional features closely matches texture appearance for humans. J. Vis. 17. 5-5. doi:10.1167/17.12.5.

Whitaker, A.J., Bastrakova, I.V., 2002. Yilgarn Craton Aeromagnetic Interpretation Map 1:1 500000 Scale. Geoscience Australia, Canberra, Australia.

Wijns, C., Perez, C., Kowalczyk, P., 2005. Theta map: edge detection in magnetic data. Geophysics 70, L39-L43. doi:10.1190/1.1988184.

Williams, G.E., Schmidt, P.W., Clark, D.A., 2004. Palaeomagnetism of iron-formation from the late palaeoproterozoic Frere formation, Earaheedy basin, western Australia: palaeogeographic and tectonic implications. Precambrian Res. 128, 367-383. doi:10.1016/j.precamres.2003.09.008.

Williams, N.C., 2009. Mass and magnetic properties for 3D geological and geophysical modelling of the southern Agnew-Wiluna Greenstone Belt and Leinster nickel deposits, Western Australia. Aust. J. Earth Sci. 56, 1111-1142. doi:10.1080/ 08120090903246220 .

Wingate, M.T.D., Pirajno, F., Morris, P.A., 2004. Warakurna large igneous province: a new Mesoproterozoic large igneous province in west-central Australia. Geology 32, 105-108. doi:10.1130/G20171.1.

Yu, L., Porwal, A., Holden, E.-J., Dentith, M.C., 2012. Towards automatic lithological classification from remote sensing data using support vector machines. Comput. Geosci. 45, 229-239. doi:10.1016/j.cageo.2011.11.019. 